\title{
Effect of vehicle speed and road surface roughness on the impact factor of simply supported bridges due to IRC Class A and B loading
}

\author{
Bindesh Nunia $^{1} \cdot$ T. Rahman ${ }^{1} \cdot$ S. Choudhury ${ }^{1} \cdot$ Prashanth Janardhan $^{1}$
}

Received: 18 July 2019 / Accepted: 8 April 2020 / Published online: 18 April 2020

(c) Springer Nature Switzerland AG 2020

\begin{abstract}
Indian Road Congress (IRC)-06 specifies consideration of impact factor for dynamic analysis of bridge loaded with Class $A$ and Class B vehicles. As per IRC-06 specifications, the impact factor is estimated based only on the span length of the bridge. In the present study, the effect of vehicle speed, road surface roughness condition and span length of the bridge on the impact factor is investigated. The dynamic response of a simply supported bridge loaded with IRC Class A and Class B vehicle loads are considered for the study. For simplifications, the vehicles are idealized as a series of moving mass spring damper system. The interaction between the bridge and vehicle is accomplished by coupling the equation of motion using the interaction force at the contact point of the wheel and bridge. The coupled equation of motion is solved using Newmark's beta method. The model is validated using past available literature. The vehicle is considered to move at a consistent speed between 20 and $100 \mathrm{~km} / \mathrm{h}$. The excitation caused due to the presence of road surface roughness at various vehicle speeds on the bridge response with span lengths varying between 20 and $100 \mathrm{~m}$ is investigated. Parametric studies are also conducted using frequency ratio. From the studies, it is observed that the response of the bridge subjected to IRC Class A vehicle is $40 \%$ higher than the response of the bridge subjected to IRC Class B vehicle. It is also observed from the parametric study that, the bridge response becomes critical when the vehicle moves at resonance speed and the amplitude increases with deterioration of road surface condition. The results of the impact factor study show that IRC-06 specifications underestimate the response of the bridge for high speed moving vehicles under different road surface conditions. The findings of this study can be utilized to update the IRC specifications at the time of analysis and design of both short and as well as long-span highway bridges.
\end{abstract}

Keywords IRC loading · Vehicle speed · Road surface condition · Impact factor · Vehicle bridge interaction · Frequency parameter

\section{Introduction}

With expanding open interest, the business activity of fast vehicles become increasingly famous. As a result of the gigantic measure of dynamic vitality conveyed by the fast vehicles, it might collaborate essentially with the extension structure and even reverberate with it in specific situations. This roused the analysts to attempt different new methods for researching the response of the vehicle bridge interaction system. The majority of the research in this area is limited to wind and earthquake loading but ignoring the effect of high-speed vehicle bridge interaction [1]. The bridge response to a moving vehicle is governed by many parameters such as bridge span, vehicle speed, the natural frequency of the bridge, road surface roughness, etc. The significant effect of these parameters is difficult to estimate due to the complex behavior of both bridge and vehicle [2]. Some of these parameters have

\footnotetext{
$\triangle$ Bindesh Nunia, bindeshchouhan@gmail.com;T. Rahman, tauhidr@nits.ac.in; S.Choudhury, chou_s@civil.nits.ac.in; Prashanth Janardhan, prashanth@civil.nits.ac.in | ${ }^{1}$ Department of Civil Engineering, NIT Silchar, Cachar District, Silchar, Assam 788010, India.
} 
been identified by the researchers recently $[3,4]$ which has a significant effect on the amplification of dynamic responses with respect to static response. Other researchers [5-11] have also investigated the complexity of vehicle bridge interaction but a single quantitative expression as a function of all these parameters has not been developed yet. In the past studies $[12,13]$, the influence of road surface irregularities has been considered and the bridge response is obtained for a truckload. Huang et al. [13] established a method for vehicle bridge interaction considering the road surface irregularities and vehicle speed. A 3D bridge-vehicle coupling model has been established by Deng and Cai [14] for simulation of bridge response to a moving vehicle. The effect of dead load and impact factor to produce the absolute maximum moment was studied by estimating the number of wheels and location of IRC Class A and Class $70 \mathrm{R}$ wheeled vehicles [15]. The impact factor of various types of bridges due to moving loads have been estimated using the vehicle bridge interaction analysis [16-21]. Banerjee et al. [22] studied the effect of corrosion on the strength and stiffness of a slab girder bridge and concluded that the moment carrying capacity of the girder reduces to lesser than the actual capacity under dead load and rated live load. Nguyen et al. [23] used the finite element method and Monte Carlo simulation for random vibration analysis of vehicle bridge interaction considering the road surface roughness profile. The authors suggested that the impact factor increases with the deterioration of road surface roughness conditions.

The vehicle can be modeled as a moving force as shown in Fig. 1a. This model is progressively powerful when the proportion of the vehicle mass to the bridge mass is little and where the response of the bridge is the primary concern. Moving mass model (Fig. 1b) is another approach used to model the moving vehicles where the vehicle load is idealized as a mass accounting for the inertia effect of the vehicle. Another model that is utilized to consider the bouncing impact of the vehicle is the moving spring-mass model (Fig. 1c). Such an impact is relied upon to be marked in the nearness of asphalt surface abnormalities. In this methodology, the vehicle is demonstrated as a mass with a spring and a damper. The structural analysis mainly consists of both static and dynamic analysis [24, 25]. Dynamic forces that excite the bridge structures are vehicle motion, earthquake, streamflow and winds $[12,26]$. At the point when a bar exposed to a moving load, the moving load changes in position along the span of the bridge, hence handling of this type of load needs to be considered carefully accounting for the dynamic effect of the vehicle [27]. In light of the Euler-Bernoulli beam theory, analytical methods have been proposed to take care of basic moving load problems [12, 28]. Using modal superposition method Wang [29] analyzed multi-span Timoshenko beams for concentrated moving load and compared with Euler-Bernoulli beam responses. Using the modal analysis Wang and Lin [30] further studied multi-span Timoshenko frames excited by a moving force. Considering the inertia of the vehicle Wu et al. [31] have consolidated the finite element and analytical methods to analyze the bridge structures subjected to moving bodies. The characteristic response spectrum and dynamic amplification factor for damped beams are estimated by Savin [32]. Including the damping effect, Michaltsos [33] has evaluated the dynamic conduct of a solitary span beam for moving loads at different speeds. Oniszczuk [34] has analyzed the case of undamped forced transverse vibration for the double-beam system. Further using the Classical modal expansion method, the problem is formulated and solved for a simply supported beam. Composite beams subjected to moving random force considering acceleration, deacceleration and constant speed are analyzed by Zibdeh and Hilal [35]. Various parameters have been considered to compute the dynamic impact factor including the position of vehicle load, vehicle weight, traveling speed, road surface conditions, road roughness correlation, number of loading lanes, etc. [12,36-38]. The standard vehicle loads in the designing of the bridge are different in different countries based on their code of practice. HS2O-44 Truck, H15-44, H2O-44, and HS15-44 are some common types of vehicles that have been considered by the analysts to investigate the bridge-vehicle interaction response [14]. However, the effect of vehicle speed and road surface roughness condition (RSC) on the dynamic response of the bridges subjected to IRC Class A and Class $B$ loading has not been studied yet which is also neglected in IRC-06.
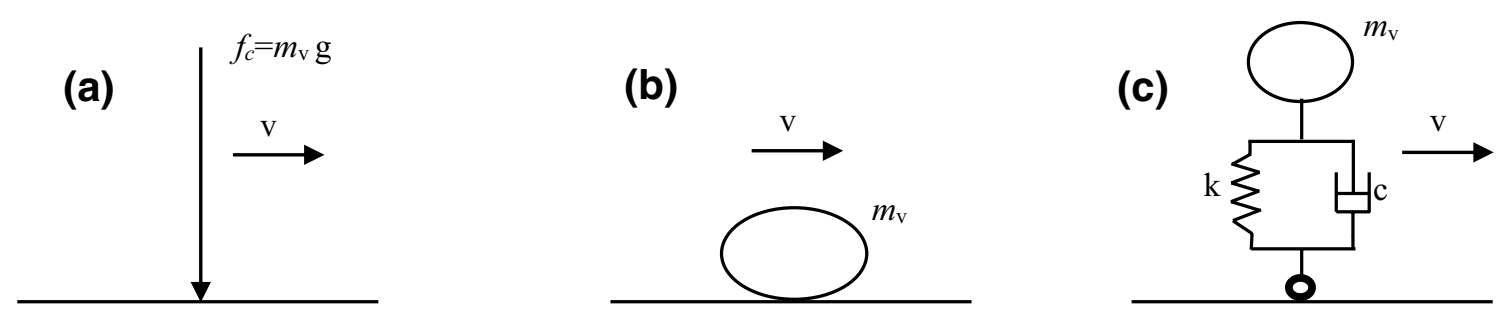

Fig. 1 a Moving force model, b moving mass model, c Spring mass damper model 


\section{Research significance}

This study focuses on understanding and evaluating the dynamic responses of bridge structure subjected to moving IRC Class A and Class B loading. As specified in the Indian Road Congress (IRC-6,2014) [39], the impact on the bridge structure due to the moving vehicle depends on the type of bridges namely Steel Bridge and Reinforced Cement Concrete (RCC) Bridge and span length. The impact factor due to the moving IRC Class A and B loading is calculated as below (IRC-06, 2014):

$I=\frac{A}{B+L}$

where $A$ and $B$ are constants and are dependent on the type of reinforced concrete bridge and steel bridge. $L$ is the span of the bridge. It appears from the Eq. (1) that, the impact is the same for a particular type of bridge irrespective of the speed of the vehicles and irregularities present on the bridge deck surface. However, past studies $[40,41]$ have shown that the speed of the vehicle and road surface roughness significantly affects the response of the bridge. In this article, the authors have addressed this problem and investigated the effect of IRC Class-A and Class- $B$ vehicle speed and road surface roughness condition (RSC) on the response of the simply supported bridges. The twovehicle loadings are shown in Fig. $2 a$, b. The loads are in ton and distances between successive loads and vehicles are in meter as per IRC- 6 specifications.

\section{Impact factor}

The impact caused in the Highway bridge structures resulting from the moving of vehicles over it is an important subject mostly concerned with the bridge engineers. When a vehicle moves over the bridge it imposes static and dynamic loads. Static loads are generated from the weight of the vehicle and the dynamic loads are generated due to the interaction of moving vehicles with bridge surfaces. Usually in the design of new bridges or at the time of evaluation of existing bridges a factor is considered to take into account the effect of dynamic vehicle load which is known as the Impact factor, where the static load is magnified by some factor to cover the dynamic effect of vehicle load. In IRC-06 (2014) specification, the impact factor is defined differently. However, the impact factor generally
Fig. 2 a IRC Class-A vehicle loading, b IRC Class-B vehicle loading

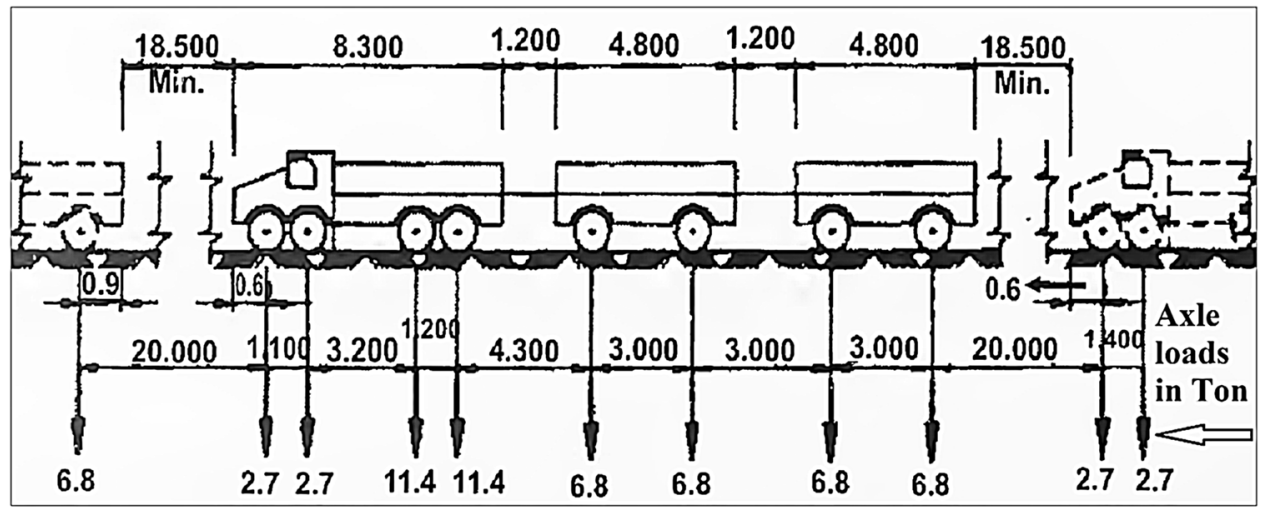

(a)

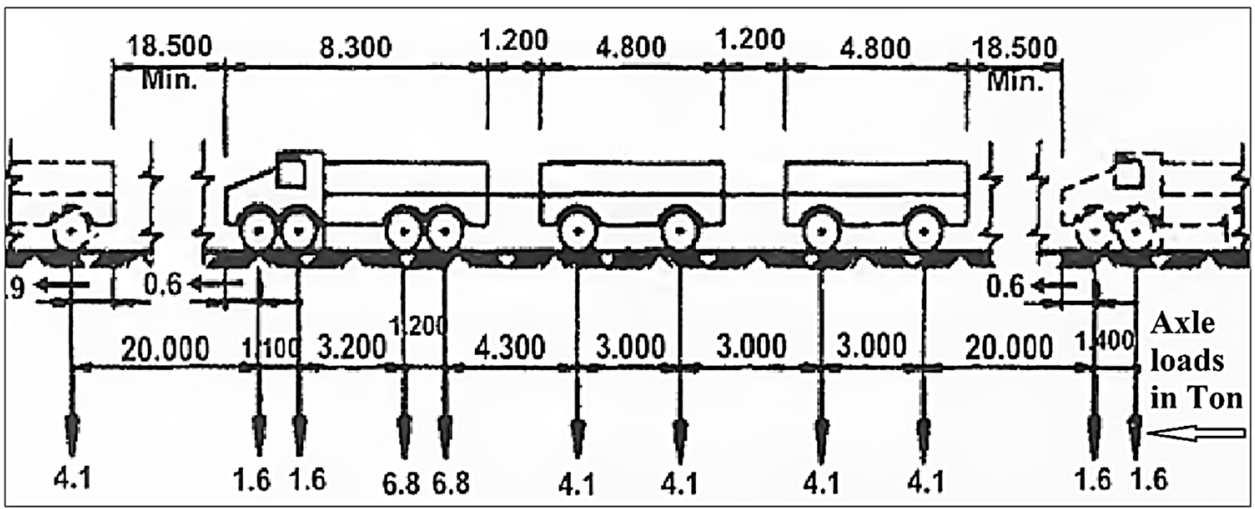

(b) 
is a function of maximum static response and maximum dynamic response as follows:

Impact factor $(\mathrm{IF})=\frac{\mathrm{u}_{\mathrm{dyn}}-\Delta_{\mathrm{st}}}{\Delta_{\mathrm{st}}}$

where $u_{d y n}$ and $\Delta_{s}$ are the maximum dynamic and static deflection at a certain location of the respectively.

\section{Vehicle bridge coupled system}

IRC class A and class B vehicle contains multiple axle loads as shown in Fig. 2. The moving load model can be used in vehicle bridge interaction analysis to estimate the bridge response due to moving vehicles. However, the moving load model cannot take into account the bouncing effect of the vehicle in the presence of road surface irregularities. To overcome this issue IRC Class A and B vehicles are idealized as a series of moving spring mass damper systems. The equation of motion of the vehicle can be written as:

$\left[\mathrm{M}_{\mathrm{v}}\right]\left\{\ddot{\mathrm{q}}_{\mathrm{v}}\right\}+\left[\mathrm{C}_{\mathrm{v}}\right]\left\{\dot{\mathrm{q}}_{\mathrm{v}}\right\}+\left[\mathrm{K}_{\mathrm{v}}\right]\left\{\mathrm{q}_{\mathrm{v}}\right\}=\left\{\mathrm{P}_{\mathrm{v}}\right\}$

where $\left[M_{v}\right],\left[C_{v}\right],\left[K_{v}\right]$ are the mass, damping and stiffness matrix of the moving spring mass damper system; $\left\{q_{v}\right\}$ is the displacement vector of the vehicle; $\left\{p_{v}\right\}$ is the vector of vehicle bridge interaction force acting on the vehicle (Fig. 3).

The mass, stiffness and damping matrix for $n$ number of moving spring mass damper system can be written as follows:

$$
\begin{aligned}
& {\left[\mathrm{M}_{\mathrm{v}}\right]=\left[\begin{array}{ccc}
\mathrm{M}_{\mathrm{v} 1} & \ldots & 0 \\
\vdots & \ddots & \vdots \\
0 & \ldots & \mathrm{M}_{\mathrm{vn}}
\end{array}\right], \quad\left[\mathrm{K}_{\mathrm{v}}\right]=\left[\begin{array}{ccc}
\mathrm{K}_{\mathrm{v} 1} & \ldots & 0 \\
\vdots & \ddots & \vdots \\
0 & \ldots & \mathrm{K}_{\mathrm{vn}}
\end{array}\right]} \\
& {\left[C_{\mathrm{v}}\right]=\left[\begin{array}{ccc}
\mathrm{C}_{\mathrm{v} 1} & \ldots & 0 \\
\vdots & \ddots & \vdots \\
0 & \ldots & C_{\mathrm{vn}}
\end{array}\right], \quad\left\{\mathrm{P}_{\mathrm{v}}\right\}=\left\{\begin{array}{c}
\mathrm{K}_{\mathrm{v} 1} \mathrm{q}_{\mathrm{v} 1}+\mathrm{C}_{\mathrm{v} 1} \dot{\mathrm{q}}_{\mathrm{v} 1} \\
\vdots \\
\mathrm{K}_{\mathrm{vn}} \mathrm{q}_{\mathrm{vn}}+\mathrm{C}_{\mathrm{v} n} \dot{\mathrm{q}}_{\mathrm{vn}}
\end{array}\right\}} \\
& \left\{q_{v}\right\}=\left\{\begin{array}{c}
q_{v 1} \\
\vdots \\
q_{v n}
\end{array}\right\}
\end{aligned}
$$

The bridge equation of motion can be written as:

$\left[M_{b}\right]\left\{\ddot{q}_{b}\right\}+\left[C_{b}\right]\left\{\dot{q}_{b}\right\}+\left[K_{b}\right]\left\{q_{b}\right\}=\left\{P_{b}\right\}$

where $\left[M_{b}\right],\left[C_{b}\right],\left[K_{b}\right]$ are the mass, damping and stiffness matrix of the bridge, $\left\{q_{b}\right\}$ is the displacement vector of the bridge, $\left\{p_{b}\right\}$ is the vehicle bridge interaction force vector acting on the bridge.

\subsection{Road surface roughness profile}

When a new bridge is constructed, its deck surface remains smooth initially but with time due to traffic movement, the deck starts deteriorating. There could be other reasons also for surface deterioration like corrosion, environmental factors, temperature variations, etc. When a vehicle moves over a deteriorated surface additional dynamic load is generated due to the interaction of moving vehicles with bridge surface. In this study, the effect of this dynamic load due to the deteriorated surface is studied. The deck surfaces roughness profile is generated by the inverse Fourier transformation of a power spectral density function (PSD). The surface profile generated here is assumed to be of zero-mean Gaussian random process. The PSD function is shown below:

$r(x)=\sum_{1}^{N} \sqrt{2 G\left(n_{k}\right) \Delta n \cos \left(2 \pi n_{k} x+\theta_{k}\right)}$

$G_{d}(n)=G_{d}\left(n_{0}\right)\left(\frac{n}{n_{0}}\right)^{-w} \quad\left(n_{1}<n<n_{2}\right)$

where $x$ is the horizontal distance of the deck surface profile varies from 0 to $L, L$ is the length of the bridge deck profile, $n_{1}$ and $n_{2}$ are the upper and lower cut off frequencies, $\Delta n=\left(n_{2}-n_{1}\right) / N$ and $N=L / B$; $B$ is the sampling frequency of the deck surface profile; $\theta_{k}$ is the random phase angle between 0 and $2 \pi$. Based on the ISO8608(2016) [42] specifications, five different categories of road surface roughness profile is generated which are classified as "Very good", "Good", "Average", "Poor" and "Very poor". The roughness coefficient $G_{d}\left(n_{0}\right)$ is

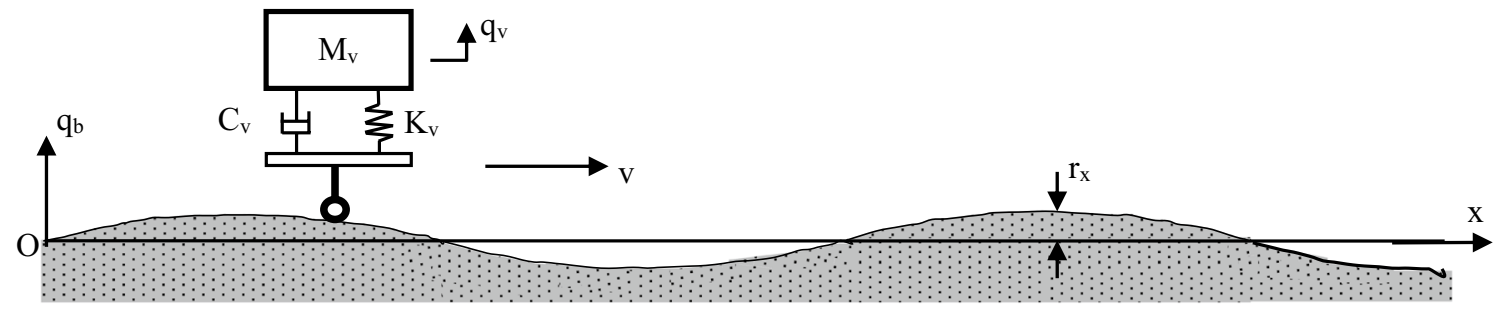

Fig. 3 Moving spring-mass model moving on the bridge 
used for the classification and is selected based on ISO 8608 specifications. The value of $G_{d}\left(n_{0}\right)$ is considered as $32 \times 10^{-6} \mathrm{~m}^{3} /$ cycle, $128 \times 10^{-6} \mathrm{~m}^{3} /$ cycle, $512 \times 10^{-6} \mathrm{~m}^{3} /$ cycle, $2048 \times 10^{-6} \mathrm{~m}^{3} /$ cycle, $8192 \times 10^{-6} \mathrm{~m}^{3} /$ cycle for "Very good", "Good", "Average", "Poor" and "Very poor" road surface condition (RSC) respectively. In the present study, the random phase angle is kept the same for different road surface conditions with varying roughness coefficient. The same signal is only multiplied by a constant to compare the bridge response obtained under different road surface conditions and also to obtain the maximum response of the bridge. The values for upper and lower cutoff frequency is taken as $0.011 \mathrm{~m}^{-1}$ and $2.83 \mathrm{~m}^{-1}$. The value of $\mathrm{N}$ is taken as 1000 . Figure 4 shows the five different categories of the road surface roughness generated to simulate the deck surface profile of the bridge.

\subsection{Complete model construction}

The equation of motion of the vehicle bridge interaction can be combined using the interaction force relationship of bridge and vehicle. Thus, the combined equation of motion of the vehicle and bridge can be written as [43]:

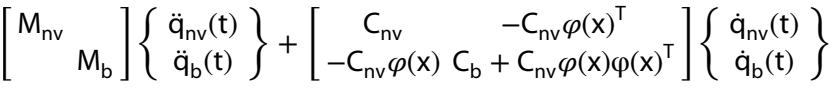

$$
\begin{aligned}
& +\left[\begin{array}{cc}
\mathrm{K}_{\mathrm{nv}} & -\mathrm{K}_{\mathrm{nv}} \varphi(\mathrm{x})^{\top}-\mathrm{C}_{\mathrm{nv}} \mathrm{V}_{\varphi^{\prime}}(\mathrm{x})^{\top} \\
-\mathrm{K}_{\mathrm{nv}} \varphi(\mathrm{x}) & \mathrm{K}_{\mathrm{b}}+\mathrm{C}_{\mathrm{nv}} \mathrm{V} \varphi(\mathrm{x}) \varphi^{\prime}(\mathrm{x})^{\top}+\mathrm{K}_{\mathrm{v}} \varphi(\mathrm{x}) \varphi(\mathrm{x})^{\top}
\end{array}\right]\left\{\begin{array}{c}
\mathrm{q}_{\mathrm{nv}}(\mathrm{t}) \\
\mathrm{q}_{\mathrm{b}}(\mathrm{t})
\end{array}\right\} \\
& =\left\{\begin{array}{c}
C_{\mathrm{nv}} \mathrm{rr}^{\prime}(\mathrm{x})+\mathrm{K}_{\mathrm{nv}} r(\mathrm{x}) \\
-\mathrm{C}_{\mathrm{nv}} \mathrm{r}^{\prime}(\mathrm{x}) \varphi(\mathrm{x})-\mathrm{K}_{\mathrm{nv}} r(\mathrm{x}) \varphi(\mathrm{x})-\mathrm{M}_{\mathrm{nv}} g \varphi(\mathrm{x})
\end{array}\right\}
\end{aligned}
$$

Here $M_{n v}, C_{n v}, K_{n v}$ is the mass, damping and stiffness matrix of the vehicle; $\varphi(\mathrm{x})$ is the mode shape of the bridge; $\mathrm{V}$ is the vehicle speed; $r(x)$ is the roughness value at position $x$ on the bridge and $r^{\prime}(x)$ is the first derivative of $r(x) ; n$ is the number of vehicle axles present on the bridge. The righthand side of the equation represents the vehicle bridge interaction forces and it is clear that the presence of road surface roughness affects the contact forces only. The above-coupled equation is solved using Newmark's beta method. The time step for the solution is taken as 0.0001 . The IRC Class A and B loading have eight axles and each axle is idealized as moving spring mass damper system. To get the desired accuracy for the bridge response first 30 modes of the bridge are considered. A MATLAB program is developed to solve the coupled equation of motion and the results are obtained in terms of displacement velocity and acceleration of the bridge.

The parametric study is conducted using a nondimensional frequency parameter $S_{n}$ which can be defined as the ratio of bridge frequency to the vehicle's driving frequency. The vehicle's driving frequency
( $\omega$ ) can be expressed as $\omega=\pi V / L$. Thus, the frequency parameter can be given as follows [44]:

$\mathrm{S}_{\mathrm{n}}=\frac{\omega}{\omega_{\mathrm{bn}}}=\frac{\pi \mathrm{V}}{\mathrm{L} \omega_{\mathrm{bn}}}$

where $L$ is the length of the bridge, $V$ is the vehicle's traveling speed, $\omega_{\text {bn }}$ is the bridge frequency of $n$th mode. As it can be seen that the frequency parameter is the function of bridge properties and vehicle speed. Thus, it can be used to study the bridge response for different bridge properties and vehicle speed. The results can be used for any values of bridge properties that yield the frequency parameter.

\section{Validation of the proposed model}

The model used here to estimate the bridge responses subjected to a moving vehicle is validated with the results obtained from the past available literature. Yang et al. [44] have estimated the dynamic response of a $25 \mathrm{~m}$ span simply supported bridge. The model presented in this paper has been used to estimate the response of the same $25 \mathrm{~m}$ span bridge used by Yang et al. [44]. Thus, for validation of the model presented in this paper, the midpoint dynamic deflection of the $25 \mathrm{~m}$ bridge for a moving force has been estimated. Yang et al. [44] have modeled the vehicle as a moving force without considering the road surface roughness. The data used by Yang et al. [44] is as follows: $E=2.87 \times 10^{6} \mathrm{kN} / \mathrm{m}^{2}$, the moment of inertia $\mathrm{I}=2.90 \mathrm{~m}^{4}$, mass per unit length, $\rho=2303 \mathrm{~kg} / \mathrm{m}$ length of bridge $L=25 \mathrm{~m}$, the mass of the vehicle $\mathrm{mv}=5750 \mathrm{~kg}$ and stiffness of the vehicle suspension is $k_{v}=1595 \mathrm{kN} / \mathrm{m}$. The damping of the vehicle suspension system and the bridge is assumed to be zero. The results obtained by the present model are compared with the results obtained by Yang et al. [44] and shown in Fig. 5. The comparisons of results obtained using our model are in good agreement with the reference model [44]. Hence, the developed model can be used to estimate the dynamic response of simply supported bridges subjected to a moving load.

\section{Numerical studies}

The numerical studies have been carried out using the moving spring mass damper model. The bridge parameters that are used in this study are given in Table 1 [45-47]. The damping of the bridge is taken as 0.025 . The vehicle mass is the same as given by the IRC-06 specification. However, to take into account the effect of road surface roughness the stiffness $\left(\mathrm{K}_{\mathrm{v}}\right)$ of the spring-mass damper 

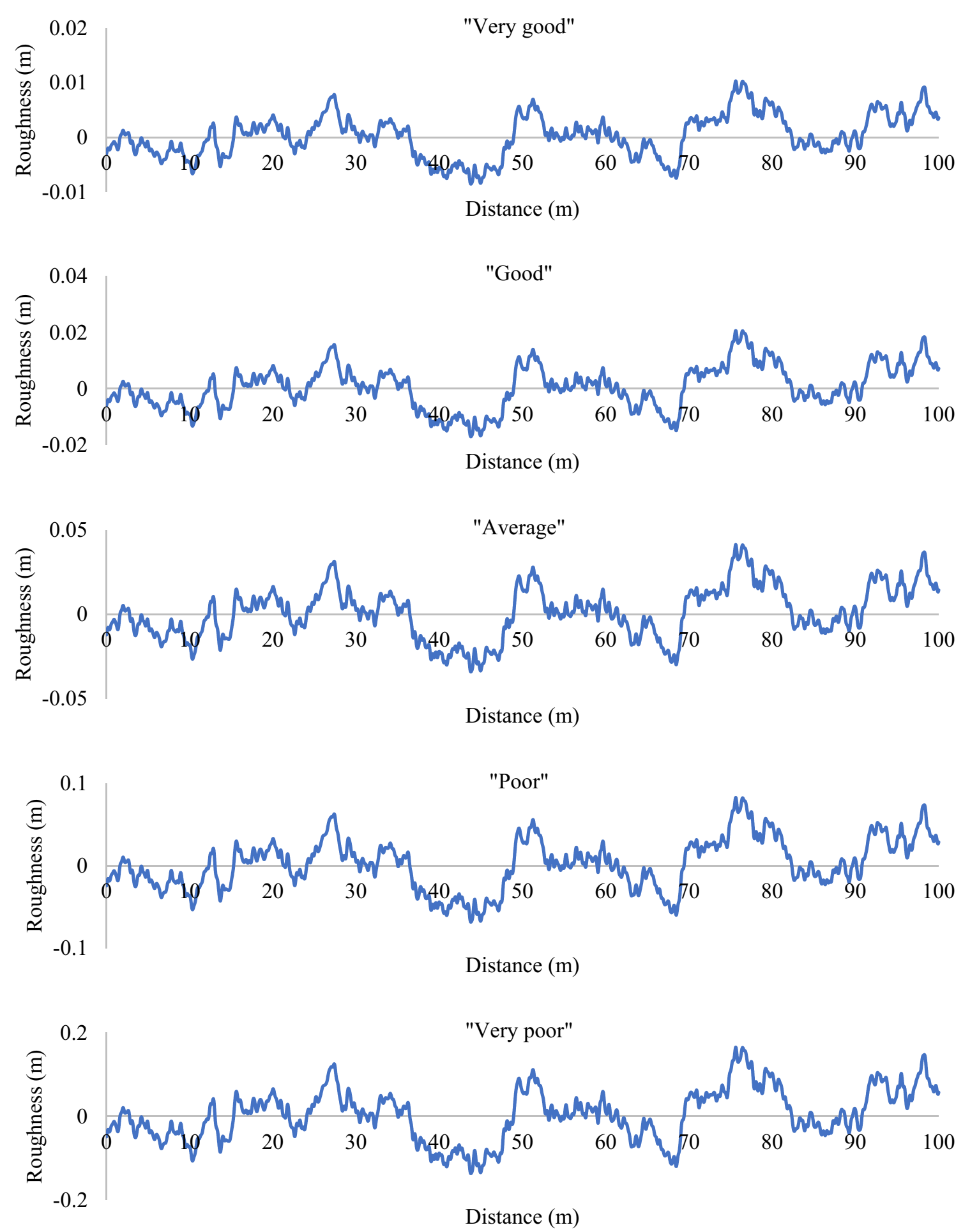

Fig. 4 Generated road surface roughness

system is taken as $8.28 \mathrm{e} 5 \mathrm{kN} / \mathrm{m}$ for IRC class-A loading and $4.968 \mathrm{e} 5 \mathrm{kN} / \mathrm{m}$ for IRC class-B loading. Here the value of $C_{v}$ is considered as zero for both the vehicle loading. The damping ratio for all the bridges is considered as 0.025 .
To check the effect of the mass-spring-damper system on the bridge response, the deflection of $25 \mathrm{~m}$ bridge obtained using the moving load model and moving spring mass damper model is compared and shown in the Fig. 6 . The responses are obtained without 


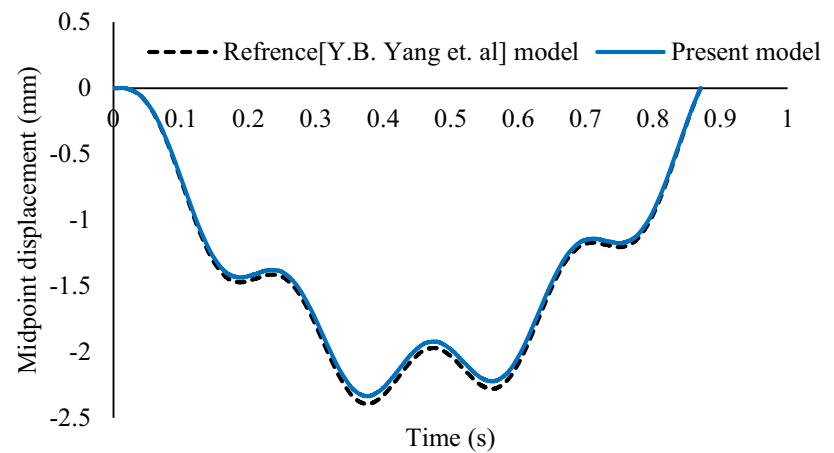

Fig. 5 Verification of the proposed model with the Ref. [44] model

considering the road surface roughness condition (RSC) because the moving load model is unable to take into account the effect of RSC. As it can be seen that both the model gives nearly the same result and hence the consideration of spring stiffness does not make much difference for the bridge response in the absence of RSC.

The bridge response is estimated for IRC class A and B loading and the results are presented in the next section. The bridge response is estimated in terms of deflection, velocity, and acceleration. The impact factor has been estimated using maximum static and dynamic deflection of the bridge. The effect of vehicle speed, span length and RSC on the deflection, velocity, acceleration and impact factor is also estimated and shown in the next sections.

\subsection{Case-I: IRC Class-A loading}

Table 2 shows the maximum static deflection due to IRCClass A loading. The deflection of the $20 \mathrm{~m}$ span bridge is higher because the flexural rigidity (EI) of the $20 \mathrm{~m}$ span bridge is less than the other bridges which indicate that the deflection of the bridge is sensitive to flexural rigidity of the bridge.

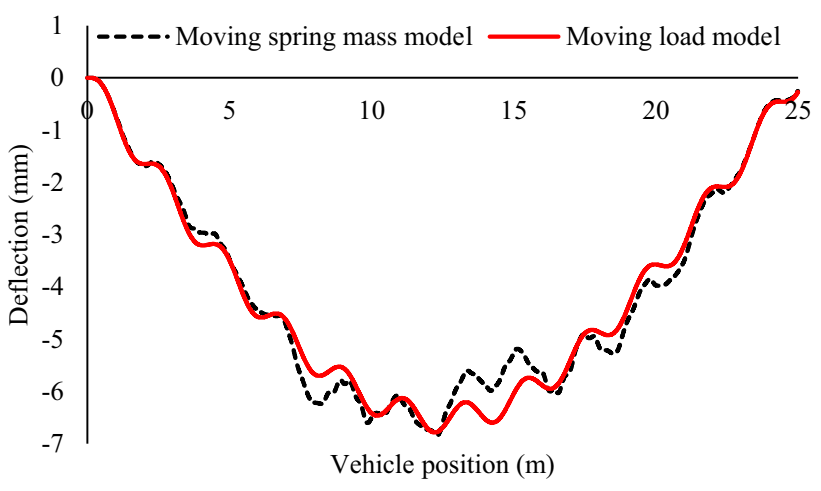

Fig. 6 Comparison of the moving load model and moving spring mass damper model at $30 \mathrm{~km} / \mathrm{h}$ speed

\subsubsection{Dynamic deflection of the bridge}

The dynamic analysis of the bridges is analyzed under different road surface conditions and vehicle speed. Figure 7a-e shows the midpoint deflection behavior of a $25 \mathrm{~m}$ span bridge under different vehicle speeds and road surface conditions. The deflection curves are shown for the vehicle speed of $20 \mathrm{~km} / \mathrm{h}, 40 \mathrm{~km} / \mathrm{h}, 70 \mathrm{~km} / \mathrm{h}$, and $100 \mathrm{~km} / \mathrm{h}$. As can be seen, the maximum deflection is observed when the vehicle reaches near the midpoint of the bridge and increases with an increase in vehicle speed. At $20 \mathrm{~km} / \mathrm{h}$ vehicle speed, the deflection curve fluctuates more with less amplitude of variability whereas at $100 \mathrm{~km} / \mathrm{h}$ speed the fluctuation is less but the amplitude is high. The reason is due to the resonance frequencies of the coupled dynamic system moving vehicle-bridge.

Further, the road surface roughness also plays an important role in the dynamic excitation of the bridge. As can be seen that with the deterioration of road surface condition (RSC) from "Very good" to "Very poor", the fluctuation of the deflection curve has increased. The amplitude of the fluctuation of the deflection curve is maximum when the road surface condition (RSC) is "Very poor" which indicates

Table 1 Properties of the bridge used in this study

\begin{tabular}{|c|c|c|c|c|c|c|c|c|c|c|c|c|}
\hline \multirow{2}{*}{$\begin{array}{l}\text { Span Length } \\
L(\mathrm{~m})\end{array}$} & \multirow{2}{*}{$\begin{array}{l}\text { Flexural rigidity } \\
\text { El }\left(\mathrm{N} \mathrm{m}^{2}\right)\end{array}$} & \multirow{2}{*}{$\begin{array}{l}\text { Mass per } \\
\text { unit length } \\
\mathrm{p}(\mathrm{kg} / \mathrm{m})\end{array}$} & \multicolumn{10}{|c|}{ Eigen frequencies of the bridge $(\mathrm{Hz})$} \\
\hline & & & $1 \mathrm{st}$ & 2nd & $3 r d$ & 4th & 5 th & 6th & 7th & 8th & 9th & 10th \\
\hline 20 & $1.9600 \times 10^{9}$ & 1000 & 5.5 & 22.0 & 49.5 & 88.0 & 137.4 & 197.9 & 269.4 & 351.9 & 445.3 & 549.8 \\
\hline 23.5 & $4.000 \times 10^{10}$ & 21,080 & 3.9 & 15.7 & 35.3 & 62.7 & 98.0 & 141.1 & 192.0 & 250.8 & 317.4 & 391.8 \\
\hline 25 & $2.719 \times 10^{10}$ & 11,150 & 3.9 & 15.7 & 35.3 & 62.8 & 98.1 & 141.3 & 192.3 & 251.2 & 317.9 & 392.5 \\
\hline 30 & $6.831 \times 10^{10}$ & 12,198 & 4.1 & 16.5 & 37.2 & 66.1 & 103.3 & 148.7 & 202.4 & 264.3 & 334.5 & 413.0 \\
\hline 50 & $1.562 \times 10^{11}$ & 14,900 & 2.0 & 8.1 & 18.3 & 32.6 & 50.9 & 73.2 & 99.7 & 130.2 & 164.8 & 203.4 \\
\hline 75 & $4.294 \times 10^{11}$ & 18,650 & 1.3 & 5.4 & 12.1 & 21.4 & 33.5 & 48.2 & 65.7 & 85.8 & 108.5 & 134.0 \\
\hline 100 & $8.857 \times 10^{11}$ & 22,400 & 1.0 & 4.0 & 8.9 & 15.8 & 24.7 & 35.6 & 48.4 & 63.2 & 80.0 & 98.8 \\
\hline
\end{tabular}


Table 2 Maximum static deflection response of the bridge in $\mathrm{mm}$

\begin{tabular}{llllllll}
\hline Bridge span & $20 \mathrm{~m}$ & $23.5 \mathrm{~m}$ & $25 \mathrm{~m}$ & $30 \mathrm{~m}$ & $50 \mathrm{~m}$ & $75 \mathrm{~m}$ & $100 \mathrm{~m}$ \\
\hline IRC Class-A Loading & $46.2138 \mathrm{~mm}$ & $3.6735 \mathrm{~mm}$ & $6.5065 \mathrm{~mm}$ & $4.4752 \mathrm{~mm}$ & $9.0596 \mathrm{~mm}$ & $11.1229 \mathrm{~mm}$ & $12.7828 \mathrm{~mm}$ \\
\hline
\end{tabular}

that the RSC contributes to the amplification of bridge response. A similar trend of variation is observed for all other bridge span and vehicle speed thus, for the sake of brevity they are not shown here.

The maximum deflection of the $25 \mathrm{~m}$ bridge for vehicle speed from 20 to $100 \mathrm{~km} / \mathrm{h}$ is estimated and shown in Fig. 8. As can be seen that the deterioration of RSC causes higher deflection irrespective of vehicle speed. On the other hand, the deflection also increases with an increase in vehicle speed from 20 to $80 \mathrm{~km} / \mathrm{h}$. The curve shows some intermediate peaks and depressions before it reaches the maximum value. The intermediate peaks are observed at $40 \mathrm{~km} / \mathrm{h}$ and $50 \mathrm{~km} / \mathrm{h}$, whereas the depressions are observed at $60 \mathrm{~km} / \mathrm{h}$ and $70 \mathrm{~km} / \mathrm{h}$ under "Very poor", "Poor", "Average", "Very good" and "Good" RSC. The drop of deflection is observed at some intermediate speed which is due to the phenomena of cancellation [48].

The maximum deflection for different span and road surface condition is estimated and compared in Fig. 9. Here a random vehicle speed of $40 \mathrm{~km} / \mathrm{h}$ is selected to show the results. Table 2 shows the deflection values for different RSC and bridge span. The deflection increases with deterioration of RSC irrespective of the bridge span. The minimum and maximum deflection are observed for "Very good" and "Very poor" RSC respectively. The minimum deflection for bridge span of $20 \mathrm{~m}, 23.5 \mathrm{~m}, 25 \mathrm{~m}$, $30 \mathrm{~m}, 50 \mathrm{~m}, 75 \mathrm{~m}$, and $100 \mathrm{~m}$ are $51.76 \mathrm{~mm}, 4.19 \mathrm{~mm}$, $7.31 \mathrm{~mm}, 4.75 \mathrm{~mm} 9.19 \mathrm{~mm}, 12.89 \mathrm{~mm}$ and $14.63 \mathrm{~mm}$ respectively. On the other hand, the maximum deflection for bridge span of $20 \mathrm{~m}, 23.5 \mathrm{~m}, 25 \mathrm{~m}, 30 \mathrm{~m}, 50 \mathrm{~m}, 75 \mathrm{~m}$, and $100 \mathrm{~m}$ is $115.89 \mathrm{~mm}, 9.81 \mathrm{~mm}, 16.97 \mathrm{~mm}, 10.53 \mathrm{~mm}$, $15.31 \mathrm{~mm}, 31.57 \mathrm{~mm}$ and $39.42 \mathrm{~mm}$ respectively.

6.1.1.1 Dynamic velocity response of the bridge The maximum velocity response of $25 \mathrm{~m}$ bridge for different vehicle speeds and RSC is shown in Fig. 10. As can be seen that the bridge velocity response increases with an increase in vehicle speed and road surface conditions. The maximum velocity of the bridge is observed at $100 \mathrm{~km} / \mathrm{h}$ speed under different road surface conditions. The maximum velocity of bridge observed under "Very good", "Good", "Average", "Poor" and "Very poor" road surface condition are $0.05 \mathrm{~m} / \mathrm{s}, 0.05 \mathrm{~m} / \mathrm{s}, 0.06 \mathrm{~m} / \mathrm{s}, 0.08 \mathrm{~m} / \mathrm{s}$ and $0.12 \mathrm{~m} / \mathrm{s}$ respectively. A similar trend of variation is observed for all other different spans of the bridge and thus is not shown.
To study the effect of the bridge span on the velocity response of the bridge, a comparison of the maximum velocity of the bridges is shown in Fig. 11. The responses are computed at $40 \mathrm{~km} / \mathrm{h}$ vehicle speed. It can be seen that the velocity response of the bridge decreases when the span increases from 50 to $100 \mathrm{~m}$. However, the trend is not similar for lower span lengths up to $50 \mathrm{~m}$. On the other hand, the velocity of the bridge increases with deterioration of RSC irrespective of span length.

6.1.1.2 Dynamic vertical acceleration of the bridge Figure 12 shows the vertical acceleration of the $25 \mathrm{~m}$ bridge under different RSC and vehicle speed. The maximum acceleration under "Very good", "Good", "Average", "Poor" and "Very poor" RSC is observed at $80 \mathrm{~km} / \mathrm{h}$. It indicates that the deterioration of RSC from the vertical acceleration gets magnified at lower vehicle speed. The maximum acceleration observed under "Very good", "Good", "Average", "Poor" and "Very poor" road surface condition are $0.96 \mathrm{~m} / \mathrm{s}^{2}, 1.00 \mathrm{~m} / \mathrm{s}^{2}, 1.08 \mathrm{~m} / \mathrm{s}^{2}, 1.25 \mathrm{~m} / \mathrm{s}^{2}$ and $1.59 \mathrm{~m} /$ $\mathrm{s}^{2}$ respectively. Figure 13 shows the maximum vertical acceleration of the $25 \mathrm{~m}$ bridges at $40 \mathrm{~km} / \mathrm{h}$ speed. It can be observed that the increase in span length causes a decrease in vertical acceleration except for a $25 \mathrm{~m}$ bridge where the acceleration response is greater than the maximum acceleration response of $23.5 \mathrm{~m}$ bridge. This indicates that the acceleration response is directly proportional to the stiffness of the bridge. Figure 14 shows the frequency spectrum of acceleration response of $25 \mathrm{~m}$ bridge due to vehicle moving at $30 \mathrm{~km} / \mathrm{h}$ speed. The responses are compared to different road surface conditions. It can be observed that the deterioration of road surface conditions causes the higher amplitude of bridge response however it does not cause excitation of other modes of the bridge. The excited bridge frequency which can be identified is $3.92 \mathrm{~Hz}$ as observed from Fig. 14. On the other hand, an increase in vehicle speed can excite the different frequencies corresponding to bridge modes as shown in Fig. 15.

6.1.1.3 Case-II: IRC Class B loading The IRC Class B loading has $40.07 \%$ less weight than the IRC Class A loading. Thus, the spring stiffness of the vehicle is also reduced in the same ratio. Here the value of vehicle spring stiffness $\left(\mathrm{K}_{\mathrm{v}}\right)$ is considered as $4.968 \mathrm{e} 5 \mathrm{kN} / \mathrm{m}$. 


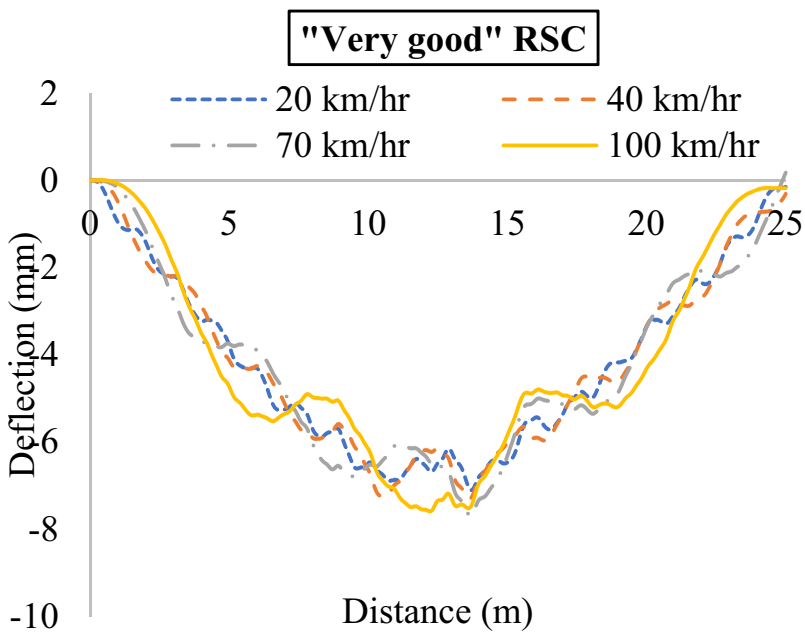

(a)

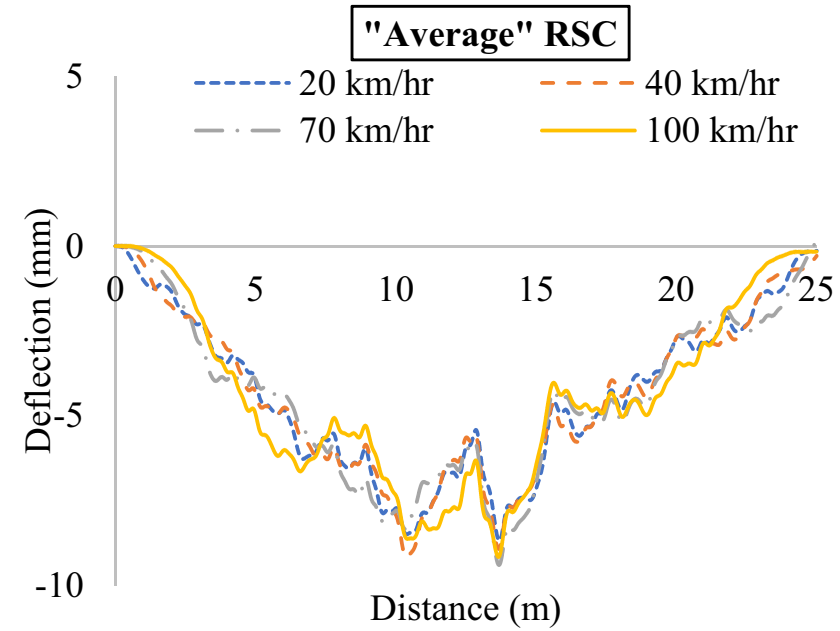

(c)

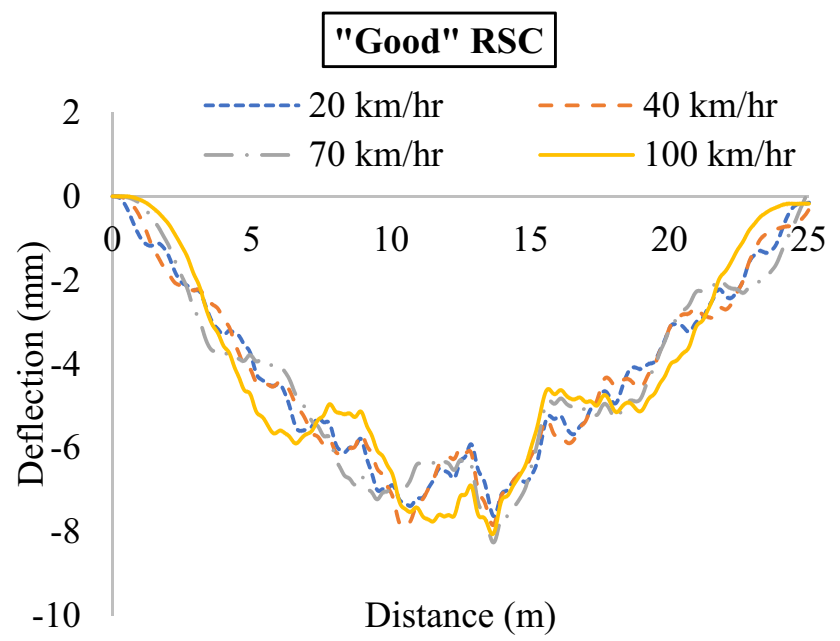

(b)

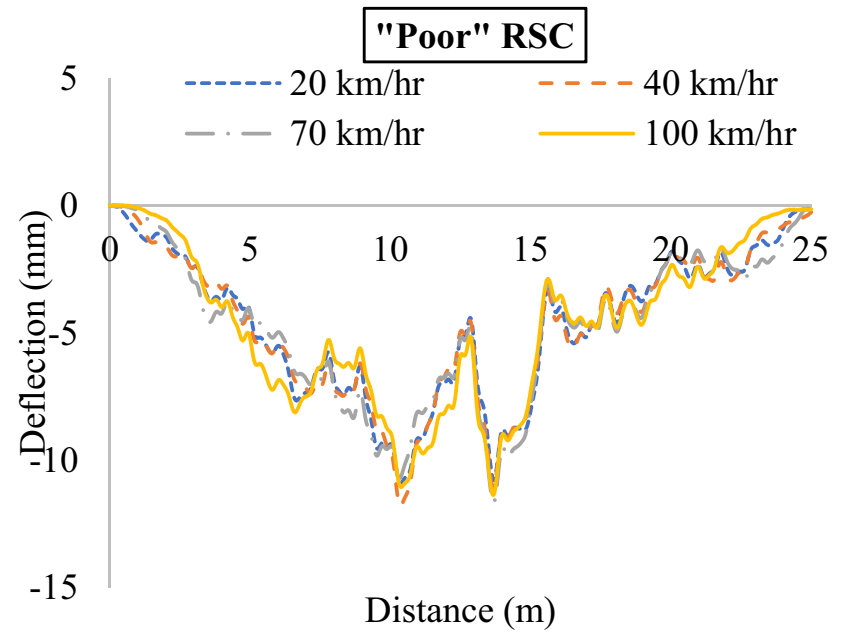

(d)

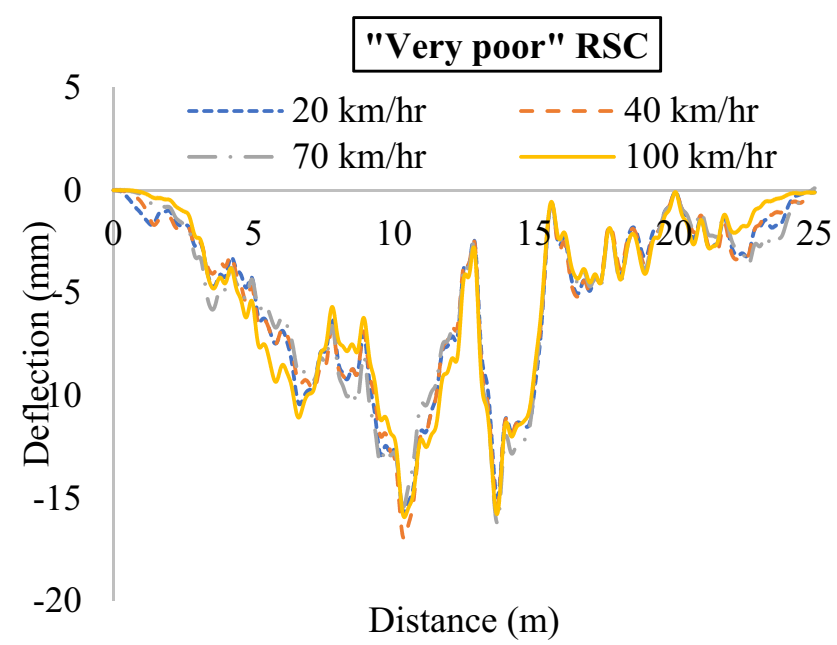

(e)

Fig. 7 Midspan deflection of $25 \mathrm{~m}$ bridge under different road surface condition and vehicle speed due to IRC Class A loading 
Fig. 8 Maximum deflection of $25 \mathrm{~m}$ bridge under different road surface condition and vehicle speed due to IRC Class A loading
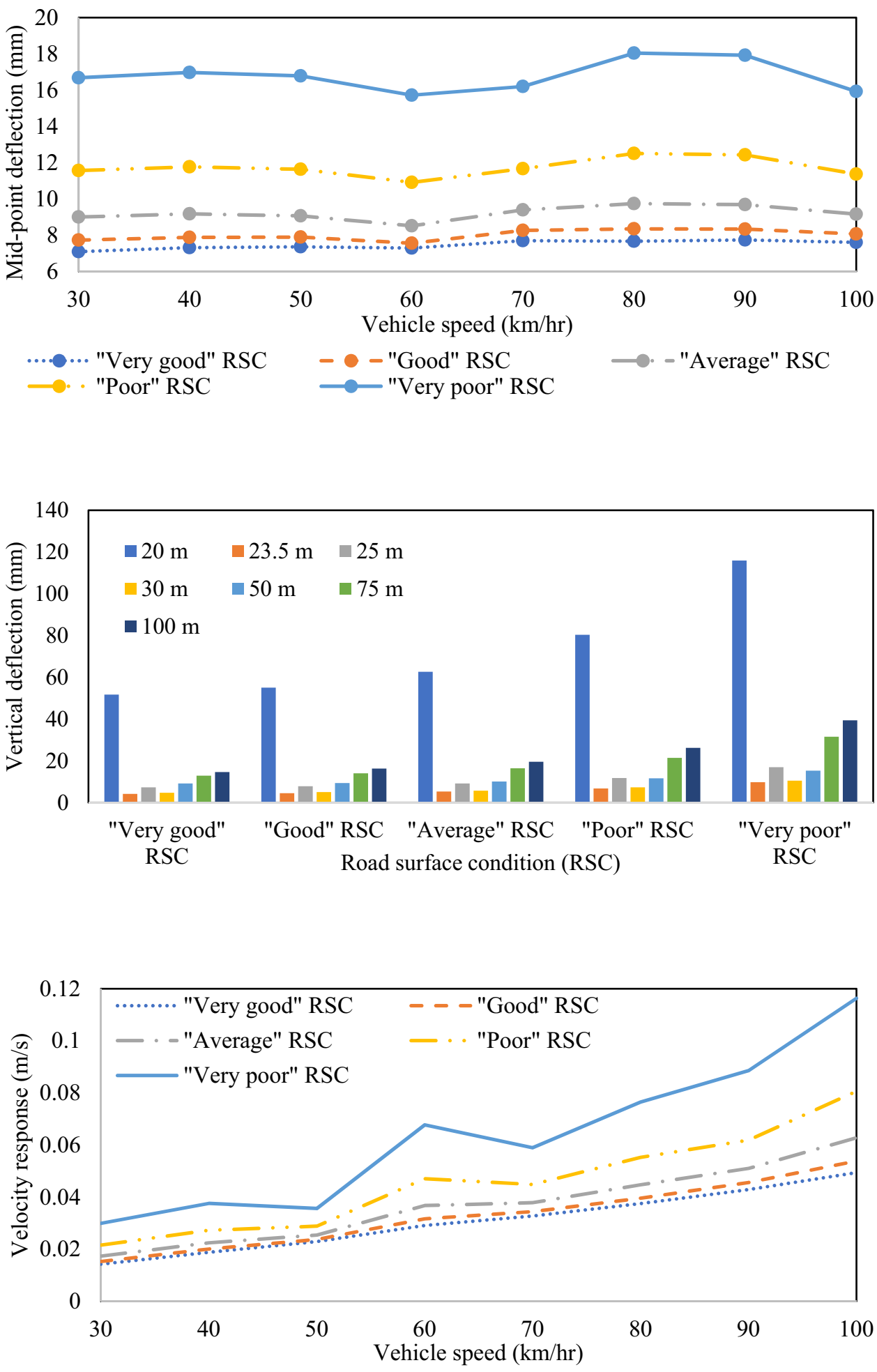

Fig. 9 Comparison of maximum deflection for different bridge span and road surface conditions at $40 \mathrm{~km} / \mathrm{h}$ vehicle speed due to IRC Class A loading

Fig. 10 Maximum velocity of $25 \mathrm{~m}$ bridge under different road surface condition due to IRC Class A loading
Table 3 shows the maximum static deflection due to IRC-Class B loading. All the parameters under study show a similar trend as observed in IRC Class A loading with variation only in the magnitude of values thus they are not shown here. However, the obtained results have been presented in "Appendix".

From the above results obtained in Sects. 6.1 and 6.2, it has been observed that the deflection, velocity, and 

maximum velocity of bridges under different road surface due to IRC Class A loading
Fig. 11 Comparison of the conditions at $40 \mathrm{~km} / \mathrm{h}$ speed
Fig. 12 Maximum vertical acceleration of $25 \mathrm{~m}$ bridge under different road surface condition due to IRC Class A loading
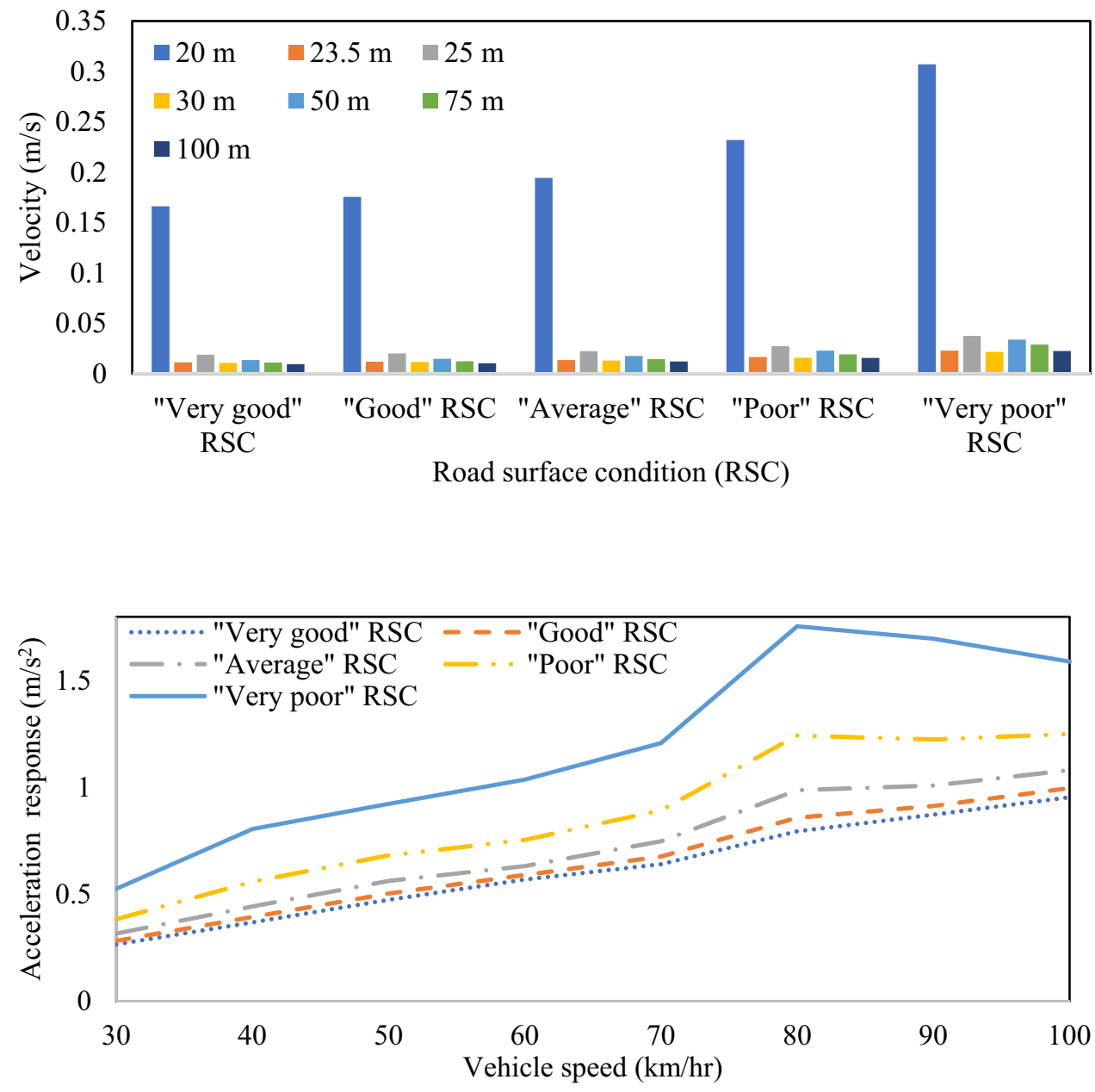

Fig. 13 Comparison of maximum acceleration of bridges under different road surface conditions at $40 \mathrm{~km} / \mathrm{h}$ speed due to IRC Class A loading

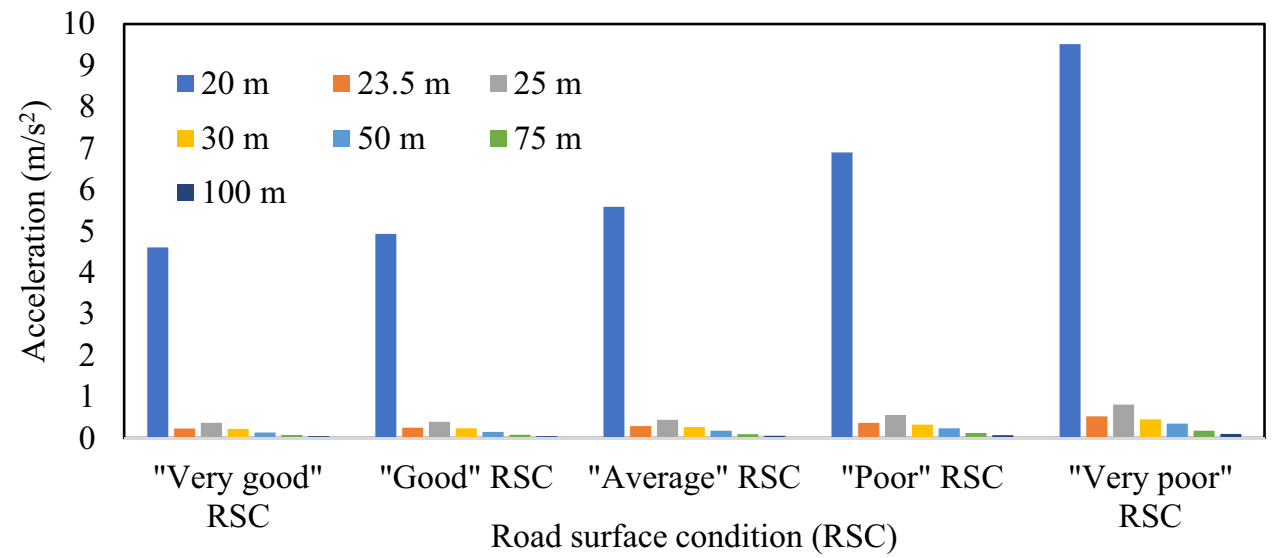

acceleration of the $20 \mathrm{~m}$ span bridge is much higher as compared to other bridges. This is because the flexural rigidity (EI) of the $20 \mathrm{~m}$ span bridge is much less than the other bridges considered in this study. Thus, it is evident that the deflection, velocity and acceleration response of the bridge is sensitive to the El parameter. The maximum deflection, velocity, and acceleration of all the bridges under different road surface conditions and the vehicle speed are presented in Tables 6, 7, 8, 9, 10 and 11 of "Appendix" and the corresponding maximum values have been highlighted. 
Fig. 14 Frequency spectrum of acceleration of $25 \mathrm{~m}$ bridge under different road surface conditions at $30 \mathrm{~km} / \mathrm{h}$ speed due to IRC Class A loading

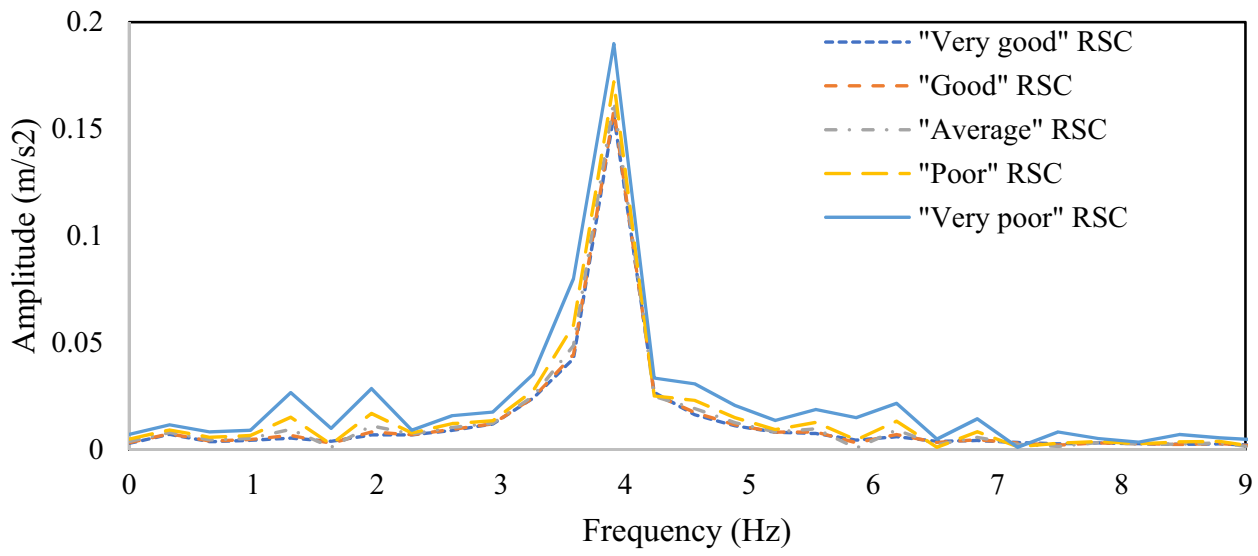

Fig. 15 Comparison of the frequency spectrum of acceleration of $25 \mathrm{~m}$ bridges under "Very good" road surface condition at $20 \mathrm{~km} / \mathrm{h}, 40 \mathrm{~km} / \mathrm{h}$, $70 \mathrm{~km} / \mathrm{h}$, and $100 \mathrm{~km} / \mathrm{h}$ speed due to IRC Class A loading

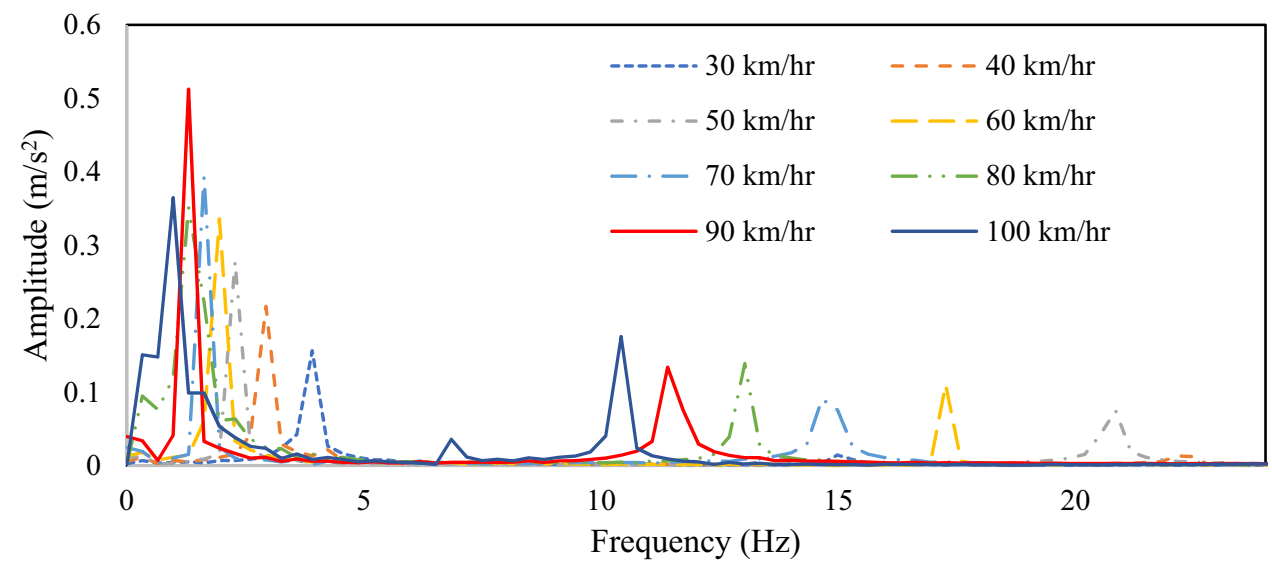

Table 3 Static deflection of bridges due to IRC Class-B loading

\begin{tabular}{llllllll}
\hline Bridge span & $20 \mathrm{~m}$ & $23.5 \mathrm{~m}$ & $25 \mathrm{~m}$ & $30 \mathrm{~m}$ & $50 \mathrm{~m}$ & $75 \mathrm{~m}$ & $100 \mathrm{~m}$ \\
\hline IRC Class-B Loading & $27.6949 \mathrm{~mm}$ & $2.2015 \mathrm{~mm}$ & $3.8992 \mathrm{~mm}$ & $2.6819 \mathrm{~mm}$ & $5.4292 \mathrm{~mm}$ & $6.6657 \mathrm{~mm}$ & $7.6605 \mathrm{~mm}$ \\
\hline
\end{tabular}

\section{Impact factor due to IRC Class A and Class B loading}

The impact factor is estimated using the maximum static and dynamic deflection of the bridge. The impact factor for both the loading condition is the same. Figure 16 shows the variation of the impact factor of bridges for different span lengths, road surface conditions, and vehicle speed. The impact factor is plotted separately for different bridge span. From the figure, it is observed that the impact factor increases when the road surface condition deteriorates from "very good" to "very poor". At the same time, the impact factor also increases with an increase in vehicle speed. However, a drop in impact factor is observed for certain intermediate vehicle speed. On the other hand, Fig. 17 shows that the impact factor of $23.5 \mathrm{~m}$ span is higher than the impact factor obtained for the $20 \mathrm{~m}$ span bridge which shows that the impact factor may not decrease with an increase in span. The impact factor may even reach greater than 1 when the road surface condition is "Very poor". The bridge response in presence of RSC initially increases and then it starts decreasing at higher vehicle speed. The vehicle speed after which the response starts decreasing is changing with the span of the bridge. As can be observed that the variation of the impact factor is different for different bridge span and vehicle speed. However, both the parameter has a significant effect on the peak response of the bridge. 

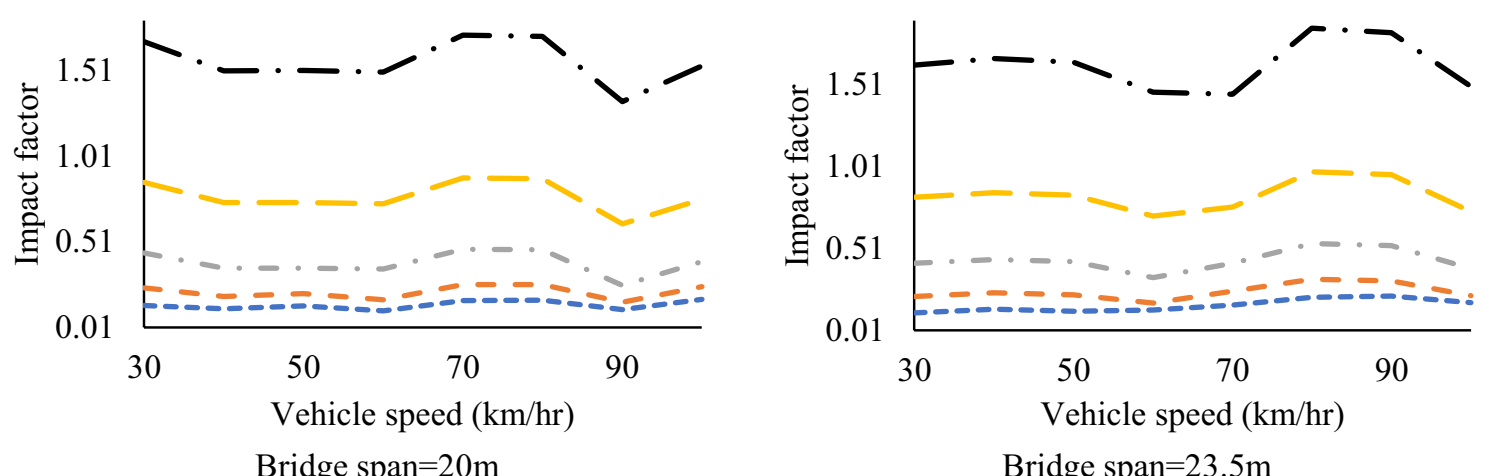

Bridge span $=20 \mathrm{~m}$

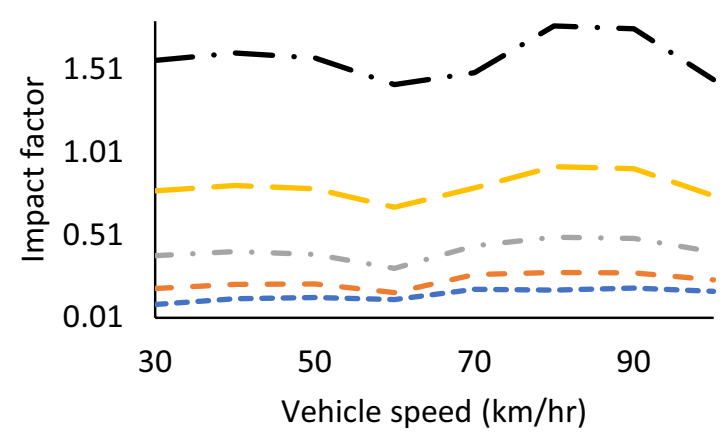

Bridge span $=25 \mathrm{~m}$

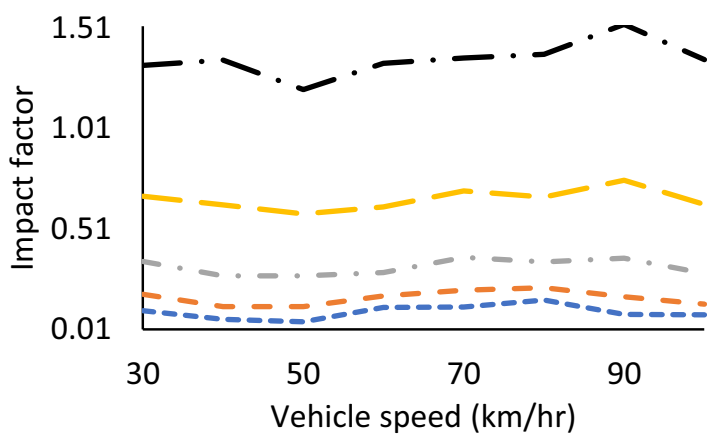

Bridge span $=30 \mathrm{~m}$
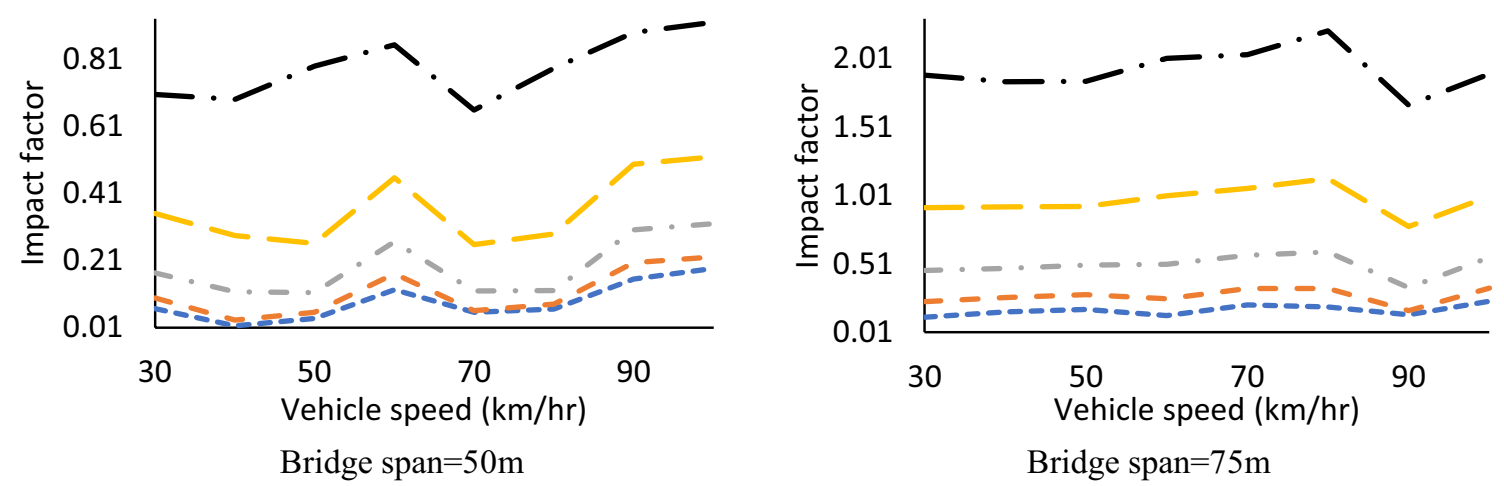

Bridge span $=75 \mathrm{~m}$
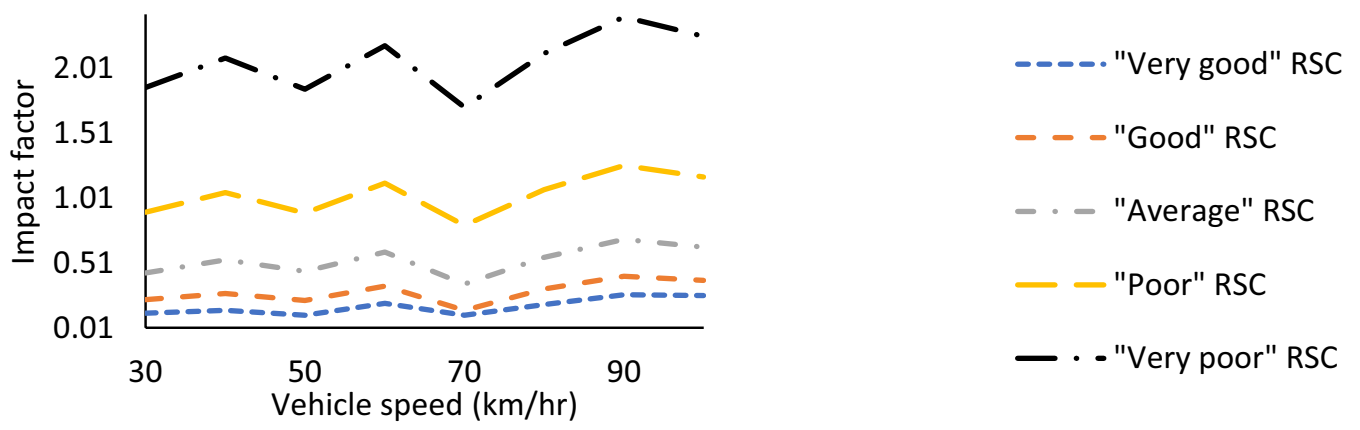

Bridge span $=100 \mathrm{~m}$

Fig. 16 Impact factor of bridges under different RSC and vehicle speed due to IRC Class A and B loading 

mum impact factor of bridges due to IRC Class-A and B loading under different RSC
Fig. 17 Comparison of maxi-

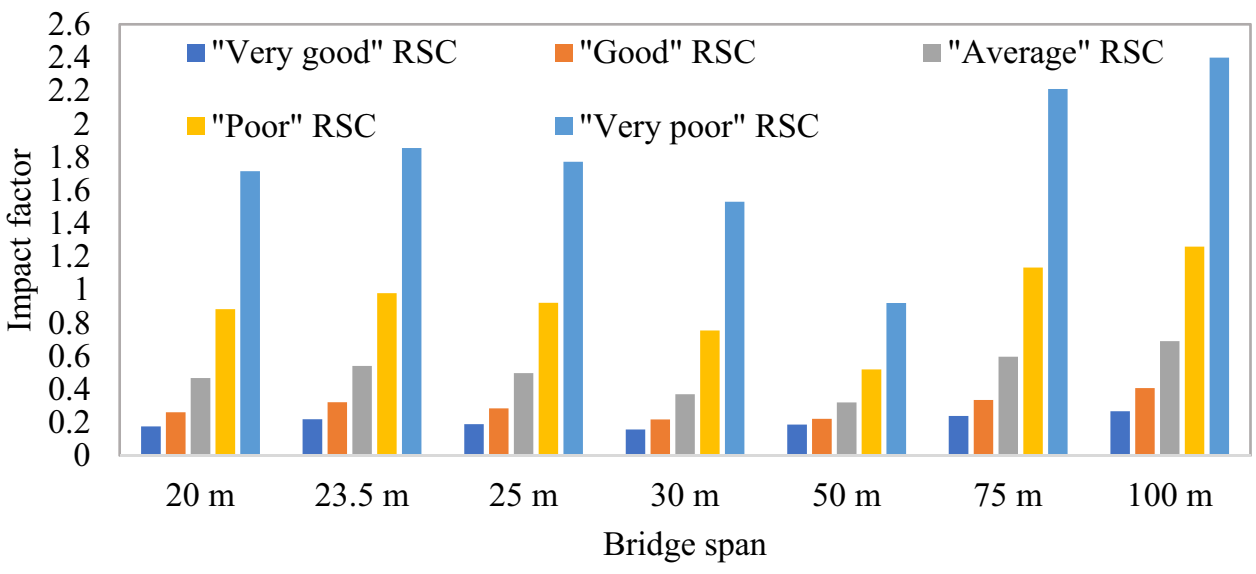

Table 4 Different frequency ratios for vehicle speed between 20 and $100 \mathrm{~km} / \mathrm{h}$ and bridge span between 20 and $100 \mathrm{~m}$

\begin{tabular}{|c|c|c|c|c|c|c|c|}
\hline \multirow{3}{*}{$\begin{array}{l}\text { Vehicle speed } \\
\text { in } \mathrm{km} / \mathrm{h}\end{array}$} & \multicolumn{7}{|c|}{ Bridge span } \\
\hline & $20 \mathrm{~m}$ & $23.5 \mathrm{~m}$ & $25 \mathrm{~m}$ & $30 \mathrm{~m}$ & $50 \mathrm{~m}$ & $75 \mathrm{~m}$ & $100 \mathrm{~m}$ \\
\hline & \multicolumn{7}{|c|}{ Frequency ratio $\left(S_{1}\right)$} \\
\hline 30 & 0.0379 & 0.0453 & 0.0425 & 0.0336 & 0.0410 & 0.0415 & 0.0422 \\
\hline 40 & 0.0505 & 0.0603 & 0.0566 & 0.0448 & 0.0546 & 0.0553 & 0.0562 \\
\hline 50 & 0.0632 & 0.0754 & 0.0708 & 0.0560 & 0.0683 & 0.0691 & 0.0703 \\
\hline 60 & 0.0758 & 0.0905 & 0.0849 & 0.0673 & 0.0819 & 0.0829 & 0.0844 \\
\hline 70 & 0.0884 & 0.1056 & 0.0991 & 0.0785 & 0.0956 & 0.0967 & 0.0984 \\
\hline 80 & 0.1011 & 0.1207 & 0.1132 & 0.0897 & 0.1092 & 0.1106 & 0.1125 \\
\hline 90 & 0.1137 & 0.1358 & 0.1274 & 0.1009 & 0.1229 & 0.1244 & 0.1265 \\
\hline 100 & 0.1263 & 0.1508 & 0.1416 & 0.1121 & 0.1365 & 0.1382 & 0.1406 \\
\hline
\end{tabular}

Fig. 18 Impact factor with the change in the frequency parameter

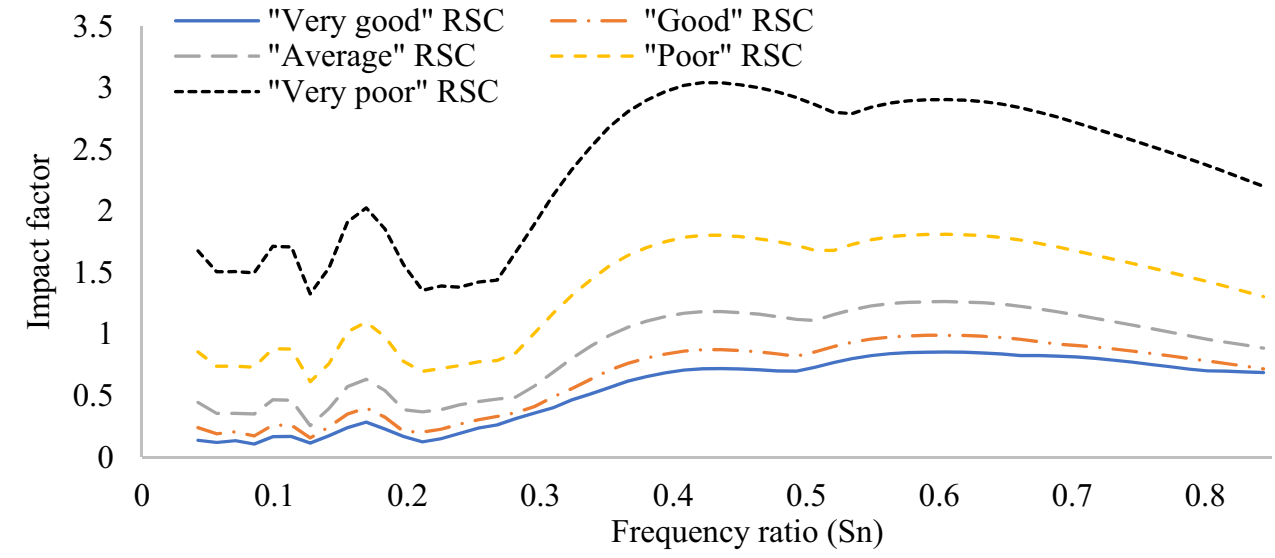

\section{Variation of impact factor with the change in the frequency ratio}

In the previous section, it has been observed that the variation of the impact factor is the same for both the IRC Class $A$ and $B$ loading cases. In this section, the effect of the frequency parameter on the impact factor of the bridge is investigated. The frequency parameter is estimated using the vehicle driving frequency and fundamental frequency of the bridge. The frequency and vehicle speed are varied to obtain the different values of the frequency parameter. The frequency parameters obtained considering the vehicle speed between 20 and $100 \mathrm{~km} / \mathrm{h}$ and bridge span between 20 and $100 \mathrm{~m}$ is shown in Table 4 . However, the $\mathrm{S}_{1}$ values are varied up to 1.4 by varying the vehicle speed 

mum impact factor with IRC-06 specification
Fig. 19 Comparison of maxi-

\begin{tabular}{lllllll}
\hline Bridge span & $\begin{array}{l}\text { IRC-06 speci- } \\
\text { fication }\end{array}$ & \multicolumn{6}{l}{ Road surface roughness condition } \\
\cline { 3 - 7 } & "Very good" & "Good" & "Average" & "Poor" & "Very poor" \\
& Impact factor of bridges & & & & \\
\hline $20 \mathrm{~m}$ & 0.1731 & 0.1743 & 0.2604 & 0.4668 & 0.8821 & 1.7142 \\
$23.5 \mathrm{~m}$ & 0.1525 & 0.2182 & 0.3211 & 0.5400 & 0.9779 & 1.8537 \\
$25 \mathrm{~m}$ & 0.1452 & 0.1887 & 0.2835 & 0.4959 & 0.9209 & 1.7711 \\
$30 \mathrm{~m}$ & 0.1250 & 0.1566 & 0.2172 & 0.3693 & 0.7536 & 1.5299 \\
\hline
\end{tabular}

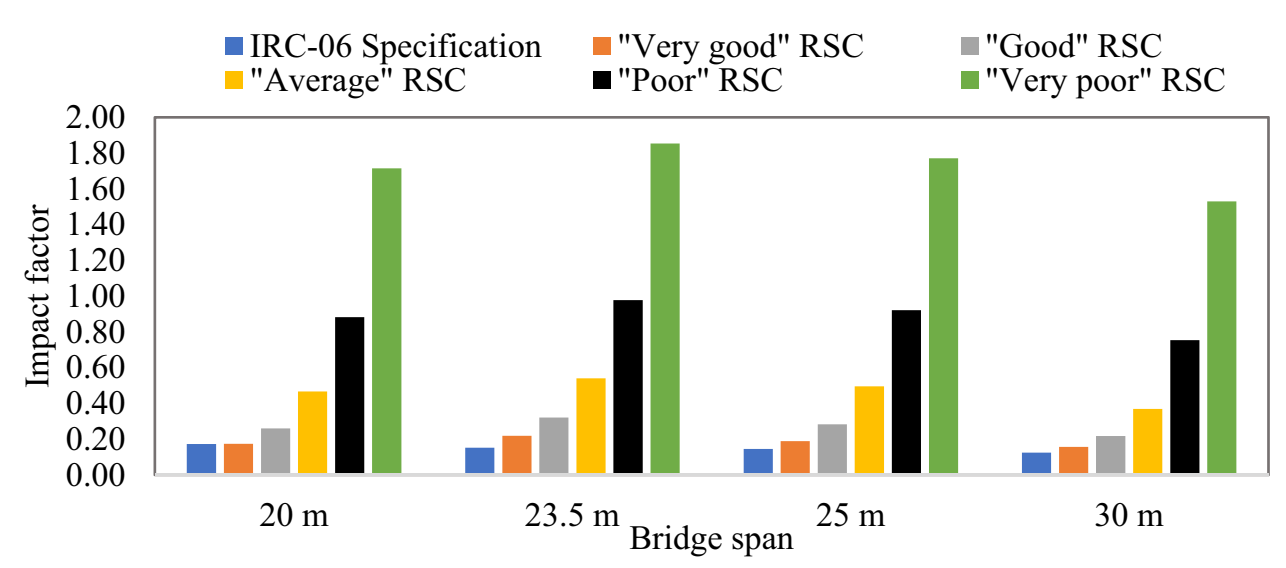

Table 5 Comparison of maximum Impact factor values obtained considering speed with IRC-06 specification the different RSC and vehicle

and bridge frequency to plot the variation of impact factor. Figure 18 shows the variation of impact factor with a change in the frequency parameter under different road surface conditions. As it can be seen that the impact factor for all RSC reaches a maximum when the $S_{1}$ value is 0.4 . Thus, in design, the resonant point i.e. $S_{1}=0.4$ should be avoided. The curve shows some intermediate peaks before $\mathrm{S}_{1}$ reaches its maximum value of 0.4 . The bridge's fundamental frequency decreases due to the added mass effect and thus the critical resonance condition occurs at $S_{1}$ values less than 1. A higher value of $S_{1}$ represents that either the vehicle is moving at higher speed or the frequency of the bridge is less. As the frequency of the bridge is a function of span length and it is a non-dimensional parameter thus it can apply to bridges with different cross-sectional properties for impact factor determination.

\section{Comparison with IRC-06 specification}

As per the IRC- 6 specifications, the impact factor for concrete bridges is estimated using Eq. (1). This equation is only valid for bridge span length up to $45 \mathrm{~m}$. Therefore, the impact factor obtained in this study for $20 \mathrm{~m}, 23.5 \mathrm{~m}$, $25 \mathrm{~m}$, and $30 \mathrm{~m}$ bridges is compared with the impact factor suggested by IRC- 6 specification. The maximum impact factor obtained considering the vehicle speed and road surface roughness condition (RSC) is compared with the impact factor values suggested in IRC-06 specification and shown in Fig. 19 and Table 5. It is clear from the figure that IRC-06 underestimates the impact factor values. It is clear from the figure that, the speed of the vehicle and road surface roughness condition plays an important role in magnifying the impact factor which is neglected in IRC-06 specification. Thus, due consideration should be made for vehicle speed and road surface roughness in estimating the impact factor for bridges.

\section{Conclusions}

A parametric study on bridge responses and impact factor to specify the effects of span length, vehicle speed and road surface roughness have been conducted. Dynamic responses and impact factors have been calculated for a simply supported bridge loaded with two types of vehicular load viz. IRC class A and class B. The vehicles were idealized as a series of moving mass spring damper system. The vehicle-bridge interaction was modeled using the coupled equation of motion and was solved by Newmark's beta method. Various speeds of vehicle ranging from 20 to $100 \mathrm{~km} / \mathrm{h}$ was considered for the study. 
The obtained research results, when compared with IRC-06 specification, shows that in most of the cases the impact factor values proposed by design code are underestimated. In the current design codes, the impact factor relations have been defined just based on span length, where there is a decrease with an increase in span length. But the results of the research show that in some conditions impact factors for bridges with a longer span length are greater than those for shorter ones.

The research results also show that vehicle speed and road surface roughness are also effective parameters in impact factor. According to achieved results, conditions for impact factors are different in different velocity ranges. The results show that with the increase in vehicle speed from 30 to $100 \mathrm{~km} / \mathrm{h}$ causes an increase in impact factor values with intermediate peaks and depressions depending on the bridge span. Hence, a parameter which includes both vehicle speed and bridge span can be a better indicator of the impact factor. The curve obtained for impact factor with respect to frequency ratio which includes both bridge frequency and vehicle speed can be considered as a modification of IRC-06 specification for accurate estimation of the impact factor of simply supported bridges. It is also observed that the maximum impact factor is obtained for the frequency ratio value of 0.4 irrespective of the road surface condition. Thus, in the design, this value should be avoided. The RSC also influences impact factor and it is seen that with deteriorated RSC, the impact factor increases drastically. Hence, to avoid high impact factor values, the RSC must be maintained at "good" or "very good" condition.

In this research, according to dynamic analysis results, it is observed that the increase in span length causes a decrease in vertical acceleration, except for a $25 \mathrm{~m}$ bridge where the acceleration response is greater than the maximum acceleration response of $23.5 \mathrm{~m}$ bridge. This indicates that the acceleration response is directly proportional to the stiffness of the bridge. The road surface roughness affects the deflection, velocity, and acceleration of the bridge for varying speeds.

In the present study, the bridge response and Impact factor values are obtained considering the bridge as simply supported. Further research can be carried out to study the bridge response and impact factor for continuous bridges subjected to IRC class A and B vehicles. Also, in the present study, the vehicle is considered to be moving with constant speed. Thus, further studies may be done with varying vehicle speeds.

Acknowledgements This is an original work and the author has not received any fund from anywhere else.

Data availability statement All data, models, and code generated or used during the study appear in the submitted article.

\section{Compliance with ethical standards}

Conflict of interest On behalf of all authors, the corresponding author states that there is no conflict of interest.

\section{Appendix}

See Tables 6, 7, 8, 9, 10 and 11 . 
Table 6 Maximum deflection of bridges under different road surface condition and vehicle speed due to IRC Class A loading

\begin{tabular}{|c|c|c|c|c|c|c|c|c|}
\hline \multirow{3}{*}{$\begin{array}{l}\text { Road surface } \\
\text { condition } \\
\text { (RSC) }\end{array}$} & \multirow{3}{*}{$\begin{array}{l}\text { Vehicle } \\
\text { speed } \\
(\mathrm{km} / \mathrm{h})\end{array}$} & \multicolumn{7}{|c|}{ Bridge span } \\
\hline & & $20 \mathrm{~m}$ & $23.5 \mathrm{~m}$ & $25 \mathrm{~m}$ & $30 \mathrm{~m}$ & $50 \mathrm{~m}$ & $75 \mathrm{~m}$ & $100 \mathrm{~m}$ \\
\hline & & \multicolumn{7}{|c|}{ Displacement response of bridge in $\mathrm{mm}$} \\
\hline \multirow[t]{8}{*}{ "Very good" } & 30 & 52.5894 & 4.1042 & 7.0860 & 4.9402 & 9.6651 & 12.4725 & 14.3362 \\
\hline & 40 & 51.7563 & 4.1879 & 7.3114 & 4.7455 & 9.1908 & 12.8908 & 14.6328 \\
\hline & 50 & 52.4375 & 4.1389 & 7.3556 & 4.6912 & 9.3900 & 13.1009 & 14.1603 \\
\hline & 60 & 51.1688 & 4.1672 & 7.2823 & 5.0116 & 10.1664 & 12.5772 & 15.3044 \\
\hline & 70 & 53.9310 & 4.2745 & 7.6915 & 5.0234 & 9.5562 & 13.4486 & 14.1443 \\
\hline & 80 & 53.9993 & 4.4520 & 7.6598 & 5.1762 & 9.6547 & 13.3072 & 15.1827 \\
\hline & 90 & 51.5225 & 4.4752 & 7.7340 & 4.8594 & 10.4588 & 12.6653 & 16.1816 \\
\hline & 100 & 54.2680 & 4.3284 & 7.5971 & 4.8483 & 10.7458 & 13.7676 & 16.0743 \\
\hline \multirow[t]{8}{*}{ “Good" } & 30 & 57.3054 & 4.4731 & 7.7240 & 5.3046 & 9.9448 & 13.7320 & 15.6634 \\
\hline & 40 & 55.0371 & 4.5507 & 7.8771 & 5.0269 & 9.3531 & 14.0672 & 16.2855 \\
\hline & 50 & 55.7742 & 4.5079 & 7.8880 & 5.0317 & 9.5573 & 14.2965 & 15.5881 \\
\hline & 60 & 54.1701 & 4.3234 & 7.5535 & 5.2672 & 10.5987 & 13.9655 & 16.9937 \\
\hline & 70 & 58.2458 & 4.5882 & 8.2588 & 5.3907 & 9.5999 & 14.7878 & 14.6290 \\
\hline & 80 & 58.2130 & 4.8530 & 8.3510 & 5.4473 & 9.7851 & 14.7830 & 16.7135 \\
\hline & 90 & 53.4471 & 4.8228 & 8.3305 & 5.2475 & 10.9014 & 12.9814 & 17.9677 \\
\hline & 100 & 57.6354 & 4.4877 & 8.0603 & 5.0801 & 11.0568 & 14.8360 & 17.5624 \\
\hline \multirow[t]{8}{*}{ "Average" } & 30 & 66.7824 & 5.2123 & 9.0026 & 6.0335 & 10.6277 & 16.2508 & 18.3178 \\
\hline & 40 & 62.6201 & 5.2969 & 9.1695 & 5.7119 & 10.1125 & 16.4199 & 19.5910 \\
\hline & 50 & 62.6627 & 5.2527 & 9.0604 & 5.7173 & 10.0947 & 16.6875 & 18.4436 \\
\hline & 60 & 62.4290 & 4.8967 & 8.5106 & 5.7857 & 11.4632 & 16.7523 & 20.3722 \\
\hline & 70 & 67.7849 & 5.2186 & 9.3934 & 6.1281 & 10.1398 & 17.5003 & 17.2021 \\
\hline & 80 & 67.6515 & 5.6571 & 9.7334 & 6.0253 & 10.1526 & 17.7427 & 19.8153 \\
\hline & 90 & 58.0608 & 5.6115 & 9.6820 & 6.1115 & 11.7865 & 14.8607 & 21.5924 \\
\hline & 100 & 64.4828 & 5.0953 & 9.1572 & 5.7723 & 11.9570 & 17.3173 & 20.8237 \\
\hline \multirow[t]{8}{*}{ "Poor" } & 30 & 85.7363 & 6.6933 & 11.5598 & 7.4913 & 12.2307 & 21.3488 & 24.2705 \\
\hline & 40 & 80.3594 & 6.7994 & 11.7656 & 7.2964 & 11.6313 & 21.4293 & 26.2019 \\
\hline & 50 & 80.3835 & 6.7425 & 11.6340 & 7.0974 & 11.4184 & 21.4696 & 24.1710 \\
\hline & 60 & 80.0699 & 6.2756 & 10.9062 & 7.2491 & 13.1921 & 22.3287 & 27.1292 \\
\hline & 70 & 86.9780 & 6.4794 & 11.6626 & 7.6088 & 11.3835 & 22.9255 & 22.9834 \\
\hline & 80 & 86.7831 & 7.2658 & 12.4981 & 7.4732 & 11.6774 & 23.7299 & 26.5019 \\
\hline & 90 & 74.5712 & 7.2020 & 12.4233 & 7.8477 & 13.5587 & 19.8073 & 28.8787 \\
\hline & 100 & 81.2996 & 6.3694 & 11.3579 & 7.3096 & 13.7605 & 22.2799 & 27.7305 \\
\hline \multirow[t]{8}{*}{ "Very Poor" } & 30 & 123.6734 & 9.6571 & 16.6741 & 10.4069 & 15.4366 & 32.1217 & 36.5178 \\
\hline & 40 & 115.8900 & 9.8057 & 16.9709 & 10.5265 & 15.3064 & 31.5715 & 39.4238 \\
\hline & 50 & 115.9247 & 9.7252 & 16.7812 & 9.8597 & 16.2065 & 31.6304 & 36.3680 \\
\hline & 60 & 115.4850 & 9.0480 & 15.7192 & 10.4449 & 16.7848 & 33.4813 & 40.6433 \\
\hline & 70 & 125.4350 & 9.0011 & 16.2010 & 10.5701 & 15.0225 & 33.7757 & 34.5811 \\
\hline & 80 & 125.1697 & 10.4831 & 18.0303 & 10.6497 & 16.1461 & 35.7044 & 39.8752 \\
\hline & 90 & 107.5920 & 10.3863 & 17.9159 & 11.3219 & 17.1128 & 29.7006 & 43.4513 \\
\hline & 100 & 117.2458 & 9.1818 & 15.9266 & 10.5320 & 17.3892 & 32.2050 & 41.5440 \\
\hline
\end{tabular}


Table 7 Maximum velocity response of bridges under different road surface condition and vehicle speed due to IRC Class A loading

\begin{tabular}{|c|c|c|c|c|c|c|c|c|}
\hline \multirow{3}{*}{$\begin{array}{l}\text { Road surface } \\
\text { condition (RSC) }\end{array}$} & \multirow{3}{*}{$\begin{array}{l}\text { Vehicle } \\
\text { speed } \\
(\mathrm{km} / \mathrm{h})\end{array}$} & \multicolumn{7}{|c|}{ Bridge span } \\
\hline & & $20 \mathrm{~m}$ & $23.5 \mathrm{~m}$ & $25 \mathrm{~m}$ & $30 \mathrm{~m}$ & $50 \mathrm{~m}$ & $75 \mathrm{~m}$ & $100 \mathrm{~m}$ \\
\hline & & \multicolumn{7}{|c|}{ Velocity response of bridge in $\mathrm{m} / \mathrm{s}$} \\
\hline \multirow[t]{8}{*}{ "Very good" } & 30 & 0.1251 & 0.0085 & 0.0143 & 0.0080 & 0.0101 & 0.0083 & 0.0071 \\
\hline & 40 & 0.1662 & 0.0113 & 0.0188 & 0.0108 & 0.0136 & 0.0112 & 0.0095 \\
\hline & 50 & 0.2095 & 0.0138 & 0.0229 & 0.0132 & 0.0170 & 0.0139 & 0.0116 \\
\hline & 60 & 0.2573 & 0.0175 & 0.0291 & 0.0166 & 0.0205 & 0.0170 & 0.0143 \\
\hline & 70 & 0.2858 & 0.0197 & 0.0328 & 0.0188 & 0.0236 & 0.0190 & 0.0168 \\
\hline & 80 & 0.3458 & 0.0226 & 0.0375 & 0.0220 & 0.0266 & 0.0226 & 0.0192 \\
\hline & 90 & 0.3815 & 0.0258 & 0.0429 & 0.0242 & 0.0310 & 0.0251 & 0.0217 \\
\hline & 100 & 0.4124 & 0.0297 & 0.0494 & 0.0281 & 0.0343 & 0.0277 & 0.0245 \\
\hline \multirow[t]{8}{*}{ "Good" } & 30 & 0.1330 & 0.0092 & 0.0153 & 0.0085 & 0.0110 & 0.0091 & 0.0076 \\
\hline & 40 & 0.1756 & 0.0121 & 0.0200 & 0.0116 & 0.0149 & 0.0123 & 0.0104 \\
\hline & 50 & 0.2234 & 0.0143 & 0.0238 & 0.0136 & 0.0187 & 0.0152 & 0.0124 \\
\hline & 60 & 0.2788 & 0.0190 & 0.0317 & 0.0181 & 0.0228 & 0.0188 & 0.0155 \\
\hline & 70 & 0.2964 & 0.0207 & 0.0345 & 0.0199 & 0.0260 & 0.0202 & 0.0184 \\
\hline & 80 & 0.3767 & 0.0237 & 0.0396 & 0.0236 & 0.0288 & 0.0249 & 0.0210 \\
\hline & 90 & 0.4068 & 0.0275 & 0.0456 & 0.0255 & 0.0343 & 0.0273 & 0.0237 \\
\hline & 100 & 0.4285 & 0.0324 & 0.0539 & 0.0306 & 0.0374 & 0.0302 & 0.0272 \\
\hline \multirow[t]{8}{*}{ "Average" } & 30 & 0.1490 & 0.0104 & 0.0174 & 0.0094 & 0.0129 & 0.0107 & 0.0088 \\
\hline & 40 & 0.1944 & 0.0135 & 0.0224 & 0.0130 & 0.0176 & 0.0145 & 0.0121 \\
\hline & 50 & 0.2515 & 0.0153 & 0.0255 & 0.0146 & 0.0223 & 0.0179 & 0.0139 \\
\hline & 60 & 0.3228 & 0.0221 & 0.0368 & 0.0211 & 0.0274 & 0.0226 & 0.0181 \\
\hline & 70 & 0.3175 & 0.0227 & 0.0379 & 0.0222 & 0.0311 & 0.0228 & 0.0217 \\
\hline & 80 & 0.4386 & 0.0267 & 0.0448 & 0.0268 & 0.0336 & 0.0294 & 0.0244 \\
\hline & 90 & 0.4576 & 0.0308 & 0.0511 & 0.0282 & 0.0413 & 0.0319 & 0.0277 \\
\hline & 100 & 0.4642 & 0.0378 & 0.0628 & 0.0357 & 0.0437 & 0.0352 & 0.0327 \\
\hline \multirow[t]{8}{*}{ "Poor" } & 30 & 0.1808 & 0.0129 & 0.0216 & 0.0112 & 0.0165 & 0.0139 & 0.0111 \\
\hline & 40 & 0.2320 & 0.0165 & 0.0273 & 0.0159 & 0.0230 & 0.0193 & 0.0156 \\
\hline & 50 & 0.3090 & 0.0173 & 0.0289 & 0.0169 & 0.0297 & 0.0232 & 0.0170 \\
\hline & 60 & 0.4109 & 0.0282 & 0.0471 & 0.0270 & 0.0365 & 0.0301 & 0.0238 \\
\hline & 70 & 0.3598 & 0.0268 & 0.0449 & 0.0266 & 0.0415 & 0.0279 & 0.0283 \\
\hline & 80 & 0.5624 & 0.0329 & 0.0553 & 0.0333 & 0.0432 & 0.0386 & 0.0313 \\
\hline & 90 & 0.5597 & 0.0373 & 0.0619 & 0.0342 & 0.0552 & 0.0422 & 0.0356 \\
\hline & 100 & 0.5458 & 0.0485 & 0.0806 & 0.0458 & 0.0564 & 0.0452 & 0.0437 \\
\hline \multirow[t]{8}{*}{ "Very Poor" } & 30 & 0.2446 & 0.0178 & 0.0299 & 0.0149 & 0.0239 & 0.0203 & 0.0160 \\
\hline & 40 & 0.3071 & 0.0229 & 0.0376 & 0.0217 & 0.0339 & 0.0289 & 0.0226 \\
\hline & 50 & 0.4265 & 0.0213 & 0.0357 & 0.0217 & 0.0445 & 0.0339 & 0.0233 \\
\hline & 60 & 0.5873 & 0.0405 & 0.0678 & 0.0388 & 0.0548 & 0.0453 & 0.0356 \\
\hline & 70 & 0.4444 & 0.0353 & 0.0590 & 0.0357 & 0.0623 & 0.0380 & 0.0415 \\
\hline & 80 & 0.8099 & 0.0454 & 0.0765 & 0.0462 & 0.0625 & 0.0568 & 0.0450 \\
\hline & 90 & 0.7638 & 0.0537 & 0.0886 & 0.0462 & 0.0829 & 0.0632 & 0.0515 \\
\hline & 100 & 0.7130 & 0.0700 & 0.1164 & 0.0661 & 0.0817 & 0.0653 & 0.0658 \\
\hline
\end{tabular}


Table 8 Maximum acceleration response of bridges under different road surface condition and vehicle speed due to IRC Class A loading

\begin{tabular}{|c|c|c|c|c|c|c|c|c|}
\hline \multirow{3}{*}{$\begin{array}{l}\text { Road surface } \\
\text { condition (RSC) }\end{array}$} & \multirow{3}{*}{$\begin{array}{l}\text { Vehicle } \\
\text { speed } \\
(\mathrm{km} / \mathrm{h})\end{array}$} & \multicolumn{7}{|c|}{ Bridge span } \\
\hline & & $20 \mathrm{~m}$ & $23.5 \mathrm{~m}$ & $25 \mathrm{~m}$ & $30 \mathrm{~m}$ & $50 \mathrm{~m}$ & $75 \mathrm{~m}$ & $100 \mathrm{~m}$ \\
\hline & & \multicolumn{7}{|c|}{ Acceleration response of bridge in $\mathrm{m} / \mathrm{s}^{2}$} \\
\hline \multirow[t]{8}{*}{ "Very good" } & 30 & 3.4353 & 0.1622 & 0.2664 & 0.1659 & 0.0986 & 0.0549 & 0.0340 \\
\hline & 40 & 4.6059 & 0.2348 & 0.3697 & 0.2244 & 0.1356 & 0.0767 & 0.0463 \\
\hline & 50 & 5.7508 & 0.2868 & 0.4752 & 0.2765 & 0.1725 & 0.0923 & 0.0591 \\
\hline & 60 & 6.8716 & 0.3437 & 0.5703 & 0.3387 & 0.2035 & 0.1129 & 0.0726 \\
\hline & 70 & 8.3960 & 0.3977 & 0.6421 & 0.3885 & 0.2391 & 0.1368 & 0.0794 \\
\hline & 80 & 9.6363 & 0.4900 & 0.7961 & 0.4590 & 0.2856 & 0.1513 & 0.0966 \\
\hline & 90 & 10.5189 & 0.5424 & 0.8733 & 0.4980 & 0.3077 & 0.1636 & 0.1142 \\
\hline & 100 & 12.1626 & 0.5714 & 0.9557 & 0.5667 & 0.3514 & 0.2012 & 0.1185 \\
\hline \multirow[t]{8}{*}{ "Good" } & 30 & 3.6936 & 0.1695 & 0.2833 & 0.1763 & 0.1045 & 0.0591 & 0.0373 \\
\hline & 40 & 4.9331 & 0.2541 & 0.3946 & 0.2386 & 0.1500 & 0.0835 & 0.0495 \\
\hline & 50 & 6.0613 & 0.3050 & 0.5047 & 0.2925 & 0.1882 & 0.0987 & 0.0639 \\
\hline & 60 & 7.1682 & 0.3549 & 0.5912 & 0.3527 & 0.2207 & 0.1216 & 0.0789 \\
\hline & 70 & 8.9280 & 0.4176 & 0.6779 & 0.4110 & 0.2658 & 0.1498 & 0.0821 \\
\hline & 80 & 10.1899 & 0.5294 & 0.8601 & 0.4826 & 0.3133 & 0.1673 & 0.1049 \\
\hline & 90 & 10.8306 & 0.5695 & 0.9144 & 0.5427 & 0.3346 & 0.1698 & 0.1235 \\
\hline & 100 & 12.8866 & 0.5745 & 0.9980 & 0.5861 & 0.3751 & 0.2144 & 0.1240 \\
\hline \multirow[t]{8}{*}{ "Average" } & 30 & 4.2101 & 0.1947 & 0.3170 & 0.2012 & 0.1213 & 0.0683 & 0.0447 \\
\hline & 40 & 5.5876 & 0.2928 & 0.4445 & 0.2671 & 0.1788 & 0.0972 & 0.0561 \\
\hline & 50 & 6.6822 & 0.3416 & 0.5635 & 0.3246 & 0.2197 & 0.1154 & 0.0733 \\
\hline & 60 & 7.8698 & 0.3861 & 0.6331 & 0.3902 & 0.2549 & 0.1418 & 0.0916 \\
\hline & 70 & 9.9921 & 0.4573 & 0.7495 & 0.4791 & 0.3190 & 0.1758 & 0.0968 \\
\hline & 80 & 11.2975 & 0.6080 & 0.9881 & 0.5298 & 0.3687 & 0.1995 & 0.1217 \\
\hline & 90 & 11.9882 & 0.6283 & 1.0101 & 0.6320 & 0.3891 & 0.1867 & 0.1446 \\
\hline & 100 & 14.6508 & 0.6208 & 1.0826 & 0.6264 & 0.4427 & 0.2409 & 0.1440 \\
\hline \multirow[t]{8}{*}{ "Poor" } & 30 & 5.2758 & 0.2451 & 0.3844 & 0.2551 & 0.1548 & 0.0903 & 0.0595 \\
\hline & 40 & 6.8965 & 0.3702 & 0.5605 & 0.3239 & 0.2364 & 0.1245 & 0.0713 \\
\hline & 50 & 8.3015 & 0.4146 & 0.6832 & 0.3888 & 0.2826 & 0.1506 & 0.0932 \\
\hline & 60 & 9.2731 & 0.4547 & 0.7558 & 0.4670 & 0.3234 & 0.1829 & 0.1170 \\
\hline & 70 & 12.1202 & 0.5368 & 0.8943 & 0.6153 & 0.4255 & 0.2278 & 0.1264 \\
\hline & 80 & 13.5127 & 0.7654 & 1.2440 & 0.6242 & 0.4795 & 0.2638 & 0.1553 \\
\hline & 90 & 15.3556 & 0.7458 & 1.2254 & 0.8108 & 0.4982 & 0.2347 & 0.1884 \\
\hline & 100 & 18.1793 & 0.7217 & 1.2517 & 0.7104 & 0.5896 & 0.2939 & 0.1841 \\
\hline \multirow[t]{8}{*}{ "Very Poor" } & 30 & 7.5984 & 0.3458 & 0.5265 & 0.3628 & 0.2219 & 0.1343 & 0.0892 \\
\hline & 40 & 9.5143 & 0.5249 & 0.8063 & 0.4547 & 0.3516 & 0.1792 & 0.1018 \\
\hline & 50 & 11.6596 & 0.5608 & 0.9240 & 0.5172 & 0.4085 & 0.2209 & 0.1335 \\
\hline & 60 & 12.5957 & 0.6256 & 1.0379 & 0.6205 & 0.4604 & 0.2651 & 0.1677 \\
\hline & 70 & 16.3765 & 0.7129 & 1.2093 & 0.8877 & 0.6385 & 0.3327 & 0.1855 \\
\hline & 80 & 17.9430 & 1.0881 & 1.7560 & 0.8252 & 0.7011 & 0.3924 & 0.2231 \\
\hline & 90 & 22.0906 & 1.0240 & 1.6977 & 1.1682 & 0.7163 & 0.3390 & 0.2761 \\
\hline & 100 & 25.2363 & 0.9515 & 1.5900 & 0.9512 & 0.8832 & 0.4169 & 0.2756 \\
\hline
\end{tabular}


Table 9 Maximum deflection of bridges under different road surface condition and vehicle speed due to IRC Class B loading

\begin{tabular}{|c|c|c|c|c|c|c|c|c|}
\hline \multirow{3}{*}{$\begin{array}{l}\text { Road surface } \\
\text { condition } \\
\text { (RSC) }\end{array}$} & \multirow{3}{*}{$\begin{array}{l}\text { Vehicle } \\
\text { speed } \\
(\mathrm{km} / \mathrm{h})\end{array}$} & \multicolumn{7}{|c|}{ Bridge span } \\
\hline & & $20 \mathrm{~m}$ & $23.5 \mathrm{~m}$ & $25 \mathrm{~m}$ & $30 \mathrm{~m}$ & $50 \mathrm{~m}$ & $75 \mathrm{~m}$ & $100 \mathrm{~m}$ \\
\hline & & \multicolumn{7}{|c|}{ Deflection response of bridge in $\mathrm{mm}$} \\
\hline \multirow[t]{8}{*}{ “Very good" } & 30 & 31.5157 & 2.4596 & 4.2465 & 2.9605 & 5.7921 & 7.4745 & 8.5914 \\
\hline & 40 & 31.0164 & 2.5097 & 4.3816 & 2.8439 & 5.5078 & 7.7252 & 8.7691 \\
\hline & 50 & 31.4246 & 2.4804 & 4.4081 & 2.8113 & 5.6272 & 7.8511 & 8.4860 \\
\hline & 60 & 30.6643 & 2.4973 & 4.3641 & 3.0033 & 6.0925 & 7.5373 & 9.1716 \\
\hline & 70 & 32.3196 & 2.5616 & 4.6094 & 3.0104 & 5.7268 & 8.0594 & 8.4764 \\
\hline & 80 & 32.3606 & 2.6680 & 4.5904 & 3.1020 & 5.7858 & 7.9747 & 9.0986 \\
\hline & 90 & 30.8763 & 2.6819 & 4.6348 & 2.9121 & 6.2677 & 7.5900 & 9.6973 \\
\hline & 100 & 32.5216 & 2.5939 & 4.5528 & 2.9055 & 6.4398 & 8.2506 & 9.6330 \\
\hline \multirow[t]{8}{*}{ "Good" } & 30 & 34.3418 & 2.6806 & 4.6288 & 3.1789 & 5.9597 & 8.2293 & 9.3867 \\
\hline & 40 & 32.9825 & 2.7272 & 4.7206 & 3.0125 & 5.6051 & 8.4302 & 9.7595 \\
\hline & 50 & 33.4242 & 2.7015 & 4.7271 & 3.0154 & 5.7275 & 8.5676 & 9.3416 \\
\hline & 60 & 32.4629 & 2.5909 & 4.5267 & 3.1565 & 6.3515 & 8.3692 & 10.1839 \\
\hline & 70 & 34.9054 & 2.7496 & 4.9493 & 3.2305 & 5.7530 & 8.8620 & 8.7668 \\
\hline & 80 & 34.8857 & 2.9083 & 5.0046 & 3.2644 & 5.8640 & 8.8591 & 10.0160 \\
\hline & 90 & 32.0297 & 2.8902 & 4.9923 & 3.1447 & 6.5330 & 7.7795 & 10.7677 \\
\hline & 100 & 34.5396 & 2.6894 & 4.8303 & 3.0444 & 6.6261 & 8.8909 & 10.5247 \\
\hline \multirow[t]{8}{*}{ "Average" } & 30 & 40.0212 & 3.1236 & 5.3950 & 3.6157 & 6.3689 & 9.7388 & 10.9774 \\
\hline & 40 & 37.5268 & 3.1743 & 5.4951 & 3.4230 & 6.0602 & 9.8401 & 11.7404 \\
\hline & 50 & 37.5523 & 3.1478 & 5.4297 & 3.4263 & 6.0496 & 10.0005 & 11.0528 \\
\hline & 60 & 37.4123 & 2.9345 & 5.1002 & 3.4672 & 6.8696 & 10.0393 & 12.2086 \\
\hline & 70 & 40.6219 & 3.1274 & 5.6293 & 3.6724 & 6.0765 & 10.4876 & 10.3088 \\
\hline & 80 & 40.5420 & 3.3902 & 5.8330 & 3.6108 & 6.0842 & 10.6328 & 11.8749 \\
\hline & 90 & 34.7945 & 3.3629 & 5.8022 & 3.6625 & 7.0634 & 8.9057 & 12.9398 \\
\hline & 100 & 38.6431 & 3.0535 & 5.4877 & 3.4592 & 7.1656 & 10.3779 & 12.4792 \\
\hline \multirow[t]{8}{*}{ "Poor" } & 30 & 51.3798 & 4.0111 & 6.9275 & 4.4894 & 7.3296 & 12.7938 & 14.5448 \\
\hline & 40 & 48.1575 & 4.0747 & 7.0509 & 4.3726 & 6.9704 & 12.8421 & 15.7022 \\
\hline & 50 & 48.1720 & 4.0406 & 6.9720 & 4.2533 & 6.8428 & 12.8663 & 14.4851 \\
\hline & 60 & 47.9840 & 3.7608 & 6.5358 & 4.3442 & 7.9058 & 13.3810 & 16.2579 \\
\hline & 70 & 52.1239 & 3.8830 & 6.9891 & 4.5598 & 6.8218 & 13.7387 & 13.7734 \\
\hline & 80 & 52.0071 & 4.3542 & 7.4898 & 4.4785 & 6.9980 & 14.2208 & 15.8820 \\
\hline & 90 & 44.6888 & 4.3160 & 7.4450 & 4.7029 & 8.1254 & 11.8701 & 17.3063 \\
\hline & 100 & 48.7210 & 3.8170 & 6.8065 & 4.3804 & 8.2464 & 13.3518 & 16.6182 \\
\hline \multirow[t]{8}{*}{ "Very Poor" } & 30 & 74.1145 & 5.7873 & 9.9924 & 6.2366 & 9.2508 & 19.2498 & 21.8842 \\
\hline & 40 & 69.4501 & 5.8763 & 10.1702 & 6.3083 & 9.1727 & 18.9201 & 23.6258 \\
\hline & 50 & 69.4709 & 5.8281 & 10.0566 & 5.9087 & 9.7122 & 18.9554 & 21.7945 \\
\hline & 60 & 69.2074 & 5.4222 & 9.4202 & 6.2594 & 10.0587 & 20.0645 & 24.3566 \\
\hline & 70 & 75.1702 & 5.3941 & 9.7089 & 6.3344 & 9.0026 & 20.2410 & 20.7236 \\
\hline & 80 & 75.0112 & 6.2823 & 10.8052 & 6.3821 & 9.6760 & 21.3968 & 23.8963 \\
\hline & 90 & 64.4773 & 6.2243 & 10.7366 & 6.7850 & 10.2553 & 17.7989 & 26.0394 \\
\hline & 100 & 70.2627 & 5.5024 & 9.5445 & 6.3116 & 10.4210 & 19.2997 & 24.8963 \\
\hline
\end{tabular}


Table 10 Maximum velocity response of bridges under different road surface condition and vehicle speed due to IRC Class B loading

\begin{tabular}{|c|c|c|c|c|c|c|c|c|}
\hline \multirow{3}{*}{$\begin{array}{l}\text { Road surface } \\
\text { condition (RSC) }\end{array}$} & \multirow{3}{*}{$\begin{array}{l}\text { Vehicle } \\
\text { speed } \\
(\mathrm{km} / \mathrm{h})\end{array}$} & \multicolumn{7}{|c|}{ Bridge span } \\
\hline & & $20 \mathrm{~m}$ & $23.5 \mathrm{~m}$ & $25 \mathrm{~m}$ & $30 \mathrm{~m}$ & $50 \mathrm{~m}$ & $75 \mathrm{~m}$ & $100 \mathrm{~m}$ \\
\hline & & \multicolumn{7}{|c|}{ Velocity response of bridge in $\mathrm{m} / \mathrm{s}$} \\
\hline \multirow[t]{8}{*}{ "Very good" } & 30 & 0.0750 & 0.0051 & 0.0085 & 0.0048 & 0.0061 & 0.0050 & 0.0042 \\
\hline & 40 & 0.0996 & 0.0068 & 0.0113 & 0.0065 & 0.0081 & 0.0067 & 0.0057 \\
\hline & 50 & 0.1255 & 0.0083 & 0.0137 & 0.0079 & 0.0102 & 0.0083 & 0.0070 \\
\hline & 60 & 0.1542 & 0.0105 & 0.0174 & 0.0100 & 0.0123 & 0.0102 & 0.0085 \\
\hline & 70 & 0.1713 & 0.0118 & 0.0196 & 0.0113 & 0.0142 & 0.0114 & 0.0101 \\
\hline & 80 & 0.2072 & 0.0135 & 0.0225 & 0.0132 & 0.0159 & 0.0135 & 0.0115 \\
\hline & 90 & 0.2286 & 0.0155 & 0.0257 & 0.0145 & 0.0186 & 0.0150 & 0.0130 \\
\hline & 100 & 0.2471 & 0.0178 & 0.0296 & 0.0168 & 0.0206 & 0.0166 & 0.0147 \\
\hline \multirow[t]{8}{*}{ "Good" } & 30 & 0.0797 & 0.0055 & 0.0092 & 0.0051 & 0.0066 & 0.0055 & 0.0046 \\
\hline & 40 & 0.1052 & 0.0072 & 0.0120 & 0.0069 & 0.0089 & 0.0074 & 0.0062 \\
\hline & 50 & 0.1339 & 0.0086 & 0.0142 & 0.0082 & 0.0112 & 0.0091 & 0.0074 \\
\hline & 60 & 0.1671 & 0.0114 & 0.0190 & 0.0108 & 0.0137 & 0.0113 & 0.0093 \\
\hline & 70 & 0.1776 & 0.0124 & 0.0207 & 0.0120 & 0.0156 & 0.0121 & 0.0110 \\
\hline & 80 & 0.2257 & 0.0142 & 0.0237 & 0.0141 & 0.0173 & 0.0149 & 0.0126 \\
\hline & 90 & 0.2438 & 0.0165 & 0.0273 & 0.0153 & 0.0206 & 0.0164 & 0.0142 \\
\hline & 100 & 0.2568 & 0.0194 & 0.0323 & 0.0184 & 0.0224 & 0.0181 & 0.0163 \\
\hline \multirow[t]{8}{*}{ "Average" } & 30 & 0.0893 & 0.0062 & 0.0104 & 0.0056 & 0.0077 & 0.0064 & 0.0053 \\
\hline & 40 & 0.1165 & 0.0081 & 0.0134 & 0.0078 & 0.0105 & 0.0087 & 0.0073 \\
\hline & 50 & 0.1507 & 0.0092 & 0.0153 & 0.0088 & 0.0134 & 0.0107 & 0.0083 \\
\hline & 60 & 0.1934 & 0.0132 & 0.0220 & 0.0126 & 0.0164 & 0.0135 & 0.0108 \\
\hline & 70 & 0.1903 & 0.0136 & 0.0227 & 0.0133 & 0.0187 & 0.0137 & 0.0130 \\
\hline & 80 & 0.2628 & 0.0160 & 0.0268 & 0.0161 & 0.0201 & 0.0176 & 0.0146 \\
\hline & 90 & 0.2743 & 0.0184 & 0.0306 & 0.0169 & 0.0247 & 0.0191 & 0.0166 \\
\hline & 100 & 0.2782 & 0.0226 & 0.0376 & 0.0214 & 0.0262 & 0.0211 & 0.0196 \\
\hline \multirow[t]{8}{*}{ "Poor" } & 30 & 0.1084 & 0.0077 & 0.0129 & 0.0067 & 0.0099 & 0.0083 & 0.0067 \\
\hline & 40 & 0.1390 & 0.0099 & 0.0164 & 0.0095 & 0.0138 & 0.0116 & 0.0094 \\
\hline & 50 & 0.1852 & 0.0104 & 0.0173 & 0.0101 & 0.0178 & 0.0139 & 0.0102 \\
\hline & 60 & 0.2463 & 0.0169 & 0.0282 & 0.0162 & 0.0219 & 0.0181 & 0.0142 \\
\hline & 70 & 0.2156 & 0.0161 & 0.0269 & 0.0159 & 0.0248 & 0.0167 & 0.0170 \\
\hline & 80 & 0.3370 & 0.0197 & 0.0331 & 0.0199 & 0.0259 & 0.0231 & 0.0187 \\
\hline & 90 & 0.3354 & 0.0224 & 0.0371 & 0.0205 & 0.0331 & 0.0253 & 0.0214 \\
\hline & 100 & 0.3271 & 0.0291 & 0.0483 & 0.0275 & 0.0338 & 0.0271 & 0.0262 \\
\hline \multirow[t]{8}{*}{ "Very Poor" } & 30 & 0.1466 & 0.0107 & 0.0179 & 0.0089 & 0.0143 & 0.0122 & 0.0096 \\
\hline & 40 & 0.1841 & 0.0137 & 0.0225 & 0.0130 & 0.0203 & 0.0173 & 0.0135 \\
\hline & 50 & 0.2556 & 0.0128 & 0.0214 & 0.0130 & 0.0267 & 0.0203 & 0.0139 \\
\hline & 60 & 0.3519 & 0.0243 & 0.0406 & 0.0233 & 0.0328 & 0.0272 & 0.0213 \\
\hline & 70 & 0.2663 & 0.0212 & 0.0353 & 0.0214 & 0.0374 & 0.0228 & 0.0249 \\
\hline & 80 & 0.4854 & 0.0272 & 0.0458 & 0.0277 & 0.0374 & 0.0341 & 0.0270 \\
\hline & 90 & 0.4577 & 0.0322 & 0.0531 & 0.0277 & 0.0497 & 0.0379 & 0.0309 \\
\hline & 100 & 0.4273 & 0.0419 & 0.0697 & 0.0396 & 0.0490 & 0.0391 & 0.0394 \\
\hline
\end{tabular}


Table 11 Maximum acceleration response of bridges under different road surface condition and vehicle speed due to IRC Class B loading

\begin{tabular}{|c|c|c|c|c|c|c|c|c|}
\hline \multirow{3}{*}{$\begin{array}{l}\text { Road surface } \\
\text { condition (RSC) }\end{array}$} & \multirow{3}{*}{$\begin{array}{l}\text { Vehicle } \\
\text { speed } \\
(\mathrm{km} / \mathrm{h})\end{array}$} & \multicolumn{7}{|c|}{ Bridge span } \\
\hline & & $20 \mathrm{~m}$ & $23.5 \mathrm{~m}$ & $25 \mathrm{~m}$ & $30 \mathrm{~m}$ & $50 \mathrm{~m}$ & $75 \mathrm{~m}$ & $100 \mathrm{~m}$ \\
\hline & & \multicolumn{7}{|c|}{ Acceleration response of bridge in $\mathrm{m} / \mathrm{s}^{2}$} \\
\hline \multirow[t]{8}{*}{ "Very good" } & 30 & 2.0587 & 0.0972 & 0.1596 & 0.0994 & 0.0591 & 0.0329 & 0.0204 \\
\hline & 40 & 2.7602 & 0.1407 & 0.2215 & 0.1345 & 0.0812 & 0.0459 & 0.0278 \\
\hline & 50 & 3.4463 & 0.1719 & 0.2848 & 0.1657 & 0.1034 & 0.0553 & 0.0354 \\
\hline & 60 & 4.1180 & 0.2060 & 0.3418 & 0.2030 & 0.1220 & 0.0676 & 0.0435 \\
\hline & 70 & 5.0315 & 0.2383 & 0.3848 & 0.2328 & 0.1433 & 0.0820 & 0.0476 \\
\hline & 80 & 5.7748 & 0.2937 & 0.4771 & 0.2751 & 0.1711 & 0.0907 & 0.0579 \\
\hline & 90 & 6.3037 & 0.3250 & 0.5233 & 0.2985 & 0.1844 & 0.0981 & 0.0684 \\
\hline & 100 & 7.2888 & 0.3424 & 0.5728 & 0.3396 & 0.2106 & 0.1206 & 0.0710 \\
\hline \multirow[t]{8}{*}{ "Good" } & 30 & 2.2135 & 0.1016 & 0.1697 & 0.1056 & 0.0626 & 0.0354 & 0.0223 \\
\hline & 40 & 2.9563 & 0.1523 & 0.2365 & 0.1430 & 0.0899 & 0.0500 & 0.0297 \\
\hline & 50 & 3.6324 & 0.1828 & 0.3024 & 0.1753 & 0.1128 & 0.0591 & 0.0383 \\
\hline & 60 & 4.2957 & 0.2127 & 0.3543 & 0.2114 & 0.1322 & 0.0729 & 0.0473 \\
\hline & 70 & 5.3504 & 0.2502 & 0.4063 & 0.2463 & 0.1593 & 0.0898 & 0.0492 \\
\hline & 80 & 6.1066 & 0.3172 & 0.5154 & 0.2892 & 0.1877 & 0.1003 & 0.0629 \\
\hline & 90 & 6.4905 & 0.3413 & 0.5480 & 0.3252 & 0.2005 & 0.1018 & 0.0740 \\
\hline & 100 & 7.7227 & 0.3443 & 0.5981 & 0.3512 & 0.2248 & 0.1285 & 0.0743 \\
\hline \multirow[t]{8}{*}{ "Average" } & 30 & 2.5230 & 0.1167 & 0.1899 & 0.1206 & 0.0727 & 0.0409 & 0.0268 \\
\hline & 40 & 3.3485 & 0.1755 & 0.2664 & 0.1600 & 0.1071 & 0.0582 & 0.0336 \\
\hline & 50 & 4.0045 & 0.2047 & 0.3377 & 0.1945 & 0.1317 & 0.0691 & 0.0440 \\
\hline & 60 & 4.7162 & 0.2314 & 0.3794 & 0.2339 & 0.1528 & 0.0850 & 0.0549 \\
\hline & 70 & 5.9880 & 0.2741 & 0.4492 & 0.2871 & 0.1912 & 0.1054 & 0.0580 \\
\hline & 80 & 6.7703 & 0.3644 & 0.5921 & 0.3175 & 0.2209 & 0.1196 & 0.0729 \\
\hline & 90 & 7.1842 & 0.3765 & 0.6053 & 0.3788 & 0.2332 & 0.1119 & 0.0866 \\
\hline & 100 & 8.7799 & 0.3720 & 0.6488 & 0.3754 & 0.2653 & 0.1444 & 0.0863 \\
\hline \multirow[t]{8}{*}{ "Poor" } & 30 & 3.1617 & 0.1469 & 0.2303 & 0.1529 & 0.0928 & 0.0541 & 0.0357 \\
\hline & 40 & 4.1329 & 0.2218 & 0.3359 & 0.1941 & 0.1417 & 0.0746 & 0.0428 \\
\hline & 50 & 4.9749 & 0.2485 & 0.4094 & 0.2330 & 0.1694 & 0.0902 & 0.0558 \\
\hline & 60 & 5.5571 & 0.2725 & 0.4529 & 0.2799 & 0.1938 & 0.1096 & 0.0701 \\
\hline & 70 & 7.2634 & 0.3217 & 0.5359 & 0.3687 & 0.2550 & 0.1365 & 0.0757 \\
\hline & 80 & 8.0978 & 0.4587 & 0.7455 & 0.3741 & 0.2873 & 0.1581 & 0.0931 \\
\hline & 90 & 9.2023 & 0.4470 & 0.7343 & 0.4859 & 0.2985 & 0.1407 & 0.1129 \\
\hline & 100 & 10.8945 & 0.4325 & 0.7501 & 0.4257 & 0.3533 & 0.1761 & 0.1103 \\
\hline \multirow[t]{8}{*}{ "Very Poor" } & 30 & 4.5535 & 0.2072 & 0.3155 & 0.2174 & 0.1330 & 0.0805 & 0.0535 \\
\hline & 40 & 5.7017 & 0.3146 & 0.4832 & 0.2725 & 0.2107 & 0.1074 & 0.0610 \\
\hline & 50 & 6.9873 & 0.3361 & 0.5538 & 0.3099 & 0.2448 & 0.1324 & 0.0800 \\
\hline & 60 & 7.5483 & 0.3749 & 0.6220 & 0.3719 & 0.2759 & 0.1589 & 0.1005 \\
\hline & 70 & 9.8140 & 0.4272 & 0.7247 & 0.5320 & 0.3827 & 0.1994 & 0.1112 \\
\hline & 80 & 10.7528 & 0.6521 & 1.0523 & 0.4945 & 0.4201 & 0.2351 & 0.1337 \\
\hline & 90 & 13.2384 & 0.6137 & 1.0174 & 0.7001 & 0.4293 & 0.2032 & 0.1655 \\
\hline & 100 & 15.1235 & 0.5702 & 0.9529 & 0.5701 & 0.5293 & 0.2498 & 0.1651 \\
\hline
\end{tabular}




\section{References}

1. Kim J, Lynch JP (2012) Experimental analysis of vehicle-bridge interaction using a wireless monitoring system and a two-stage system identification technique. Mech Syst Signal Process 28:3-19

2. Humar J, Kashif AH (1995) Dynamic response analysis of slabtype bridges. J Struct Eng 121(1):48-62

3. Deng L, Yu Y, Zou QL, Cai CS (2015) State-of-the-art review on dynamic impact factors of highway bridges. J Bridge Eng 20(5):04014080

4. Yu Y, Cai CS, Deng L (2016) State-of-the-art review on bridge weigh-in-motion technology. Adv Struct Eng 19(9):1514-1530

5. Cantieni R (1984) Dynamic load testing of highway bridges. Transp Res Rec 950:141-148

6. Chan THT, O'Connor C (1990) Wheel loads from highway bridge strains: field studies. Eng Struct 116(7):1751-1771

7. Sennah KM, Zhang X, Kennedy JB (2004) Impact factors for horizontally curved composite box girder bridges. J Bridge Eng 9(6):512-520

8. Ding L, Hao H, Zhu X (2009) Evaluation of dynamic vehicle axle loads on bridges with different surface conditions. J Sound Vib 323(3-5):826-848

9. Hamidi SA, Danshjoo F (2010) Determination of impact factor for steel railway bridges considering simultaneous effects of vehicle speed and axle distance to span length ratio. Eng Struct 32(5):1369-1376

10. Caprani C (2012) Lifetime highway bridge traffic load effect from a combination of traffic states allowing for dynamic amplification. J Bridge Eng 18(9):901-909

11. Wang B, He H (2017) Vehicle-bridge interaction analysis based on the ANCF quasi-conforming plate technique. IOP Conf Ser Mater Sci Eng 216:1-5

12. Chang $D$, Lee $H$ (1994) Impact factors for simple-span highway girder bridges. J Struct Eng 120(3):704-715

13. Huang D, Wang TL, Shahawy M (1992) Impact studies of multi girder concrete bridges. J Struct Eng 119(8):2387-2402

14. Deng L, Cai CS (2010) Development of dynamic impact factor for performance evaluation of existing multi-girder concrete bridges. Eng Struct 32(1):21-31

15. Gupta T, Kumar MJ (2017) Influence of distributed dead loads on vehicle position for maximum moment in simply supported bridges. Inst Eng India Ser A 98:201. https://doi. org/10.1007/s40030-017-0188-0

16. Fafard M, Laflamme M, Savard M, Bennur M (1998) Dynamic analysis of existing continuous bridge. J Bridge Eng 3(1):28-37

17. Zheng XJ, Wu JJ, Zhou Y (2003) Effect of spring nonlinearity on dynamic stability of a controlled maglev vehicle and its guideway system. J Sound Vib 279(1-2):201-215

18. Mohseni I, Khalim AR, Nikbakht E (2014) Effectiveness of skewness on dynamic impact factor of concrete multicell box-girder bridges subjected to truckloads. Arab J Sci Eng 39(8):6083-6097

19. Ashebo DB, Chan THT, Yu L (2007) Evaluation of dynamic loads on a skew box girder continuous bridge. Part I: field test and modal analysis. Eng Struct 29(6):1052-1063

20. Deng L, He W, Shao Y (2015) Dynamic impact factors for shear and bending moment of simply supported and continuous concrete girder bridges. J Bridge Eng 20(11), article 04015005

21. Zhang X, Sennah K, Kennedy JB (2003) Evaluation of impact concrete-steel cellular straight bridges. Eng Struct 25(3):313-321

22. Banerjee S, Sengupta AK (2012) A methodology to assess the degradation in the structural response of the deck of a reinforced concrete road bridge due to corrosion of reinforcing steel. J Inst Eng India Ser A 93:87

23. Nguyen XT, Yukihisa K, Nguyen DT (2017) Random dynamic response analysis of bridge subjected to moving vehicles. Int J Eng Res Technol (IJERT) 6(06):1111-1118

24. Brady SP, O'Brien EJ, Žnidarič A (2006) Effect of vehicle velocity on the dynamic amplification of a vehicle crossing a simply supported bridge. J Bridge Eng 11(2):241-249

25. Yau JD (2010) Vehicle/bridge interactions of a rail suspension bridge considering support movements. Int J Interact Multiscale Mech 2(3):263-276

26. Kawatani M, Kim CW, Yasui K (2007) Seismic response of a highway bridge under traffic loadings. In: Proceedings of Pacific structural steel conference 2007: steel structures in natural hazards, Wairakei, New Zealand, March 13-16, pp 183-188

27. Rahman T, Chaitanya BS (2015) Comparative study of the responses of the vehicle-bridge interaction system in India. In: International conference on sustainable energy and built environment 12-13 March 2015 VIT Tamilnadu, ASCE Indian section

28. Xiang T, Zhao R (2005) Dynamic interaction analysis of the vehicle-bridge system using transfer matrix method. Int J Struct Eng Mech 20(1):111-121

29. Wang TL, Huang D, Shahawy M (1992) Dynamic response of multigirder bridges. J Struct Eng 118(8):2222-2238

30. Wang RT, Lin JS (1998) The vibration of multi-span Timoshenko frames due to moving loads. J Sound Vib 212(3):417-434

31. Wu JJ, Whittaker AR, Cartmell MP (2001) Dynamic responses of structures to moving bodies using combined finite element and analytical methods

32. Savin E (2001) Dynamic amplification factor and response spectrum for the Evaluation of vibrations of beams under successive moving loads. J Sound Vib 248(2):267-288

33. Michaltsos GT (2002) Dynamic behavior of a single-span beam subjected to loads moving with variable speeds. J Sound Vib 258(2):359-372

34. Oniszczuk Z (2003) Forced transverse vibrations of an elastically connected complex simply supported double-beam system. J Sound Vib 264(2):273-286

35. Zibdeh \& Hilal (2003) Stochastic vibration of laminated composite coated beam traversed by a random moving load. Eng Struct 25(3):397-404

36. Yang YB, Liao SS, Lin BH (1995) Impact formulas for vehicles moving over simple and continuous beams. J Struct Eng ASCE 121(11):1644-1650

37. Liu C, Huang D, Wang TL (2002) Analytical dynamic impact study based on correlated road roughness. Comput Struct 80:1639-1650

38. Huang DZ, Wang TL (1992) Impact analysis of cable-stayed bridges. Comput Struct 43(5):897-908

39. IRC-06 (2014) Standard specifications and code of practice for road bridges, Section II-loads and stresses (Fourth Revision)

40. Hamidi SA, Danshjoo F (2010) Determination of impact factor for steel railway bridges considering simultaneous effects of vehicle speed and axle distance to span length ratio. Eng Struct 32:1369-1376

41. Maa L, Zhanga W, Hanb WS, Liu JX (2019) Determining the dynamic amplification factor of multi-span continuous box girder bridges in highways using vehicle-bridge interaction analyses. Eng Struct 181:47-59

42. International Organization for Standardization (ISO) (2016) Mechanical vibration-road surface profiles-reporting of measured data. ISO 8608: 2016 (E), ISO. Geneva

43. Chang KC, Wu FB, Yang YB (2010) Effect of road surface roughness on indirect approach for measuring bridge frequencies from a passing vehicle. Interact Multiscale Mech 3(4):299-308 
44. Yang YB, Lin CW (2005) Vehicle-bridge interaction dynamics and potential applications. J Sound Vib 284(1-2):205-226

45. Carlos CR, Carlos R. Modelling the interaction effects of the highspeed train-track-bridge system using Adina. In: 5th international conference on mechanics and materials in design

46. Salvo VD, Muscolino G, Palmeri A (2010) Substructure approach tailored to the dynamic analysis of multi-span continuous beams under moving loads. J Sound Vib 329(15):3101-3120

47. Johansson C, Pacosteab C, Karoumia R (2013) Closed-form solution for the mode superposition analysis of the vibration in multi-span beam bridges caused by concentrated moving loads. Comput Struct 119(1):85-94
48. Yang YB, Yau JD, Wu YS (2004) Vehicle bridge interaction dynamics with application to high-speed railways. World Scientific, Singapore

Publisher's Note Springer Nature remains neutral with regard to jurisdictional claims in published maps and institutional affiliations. 